\title{
A Review of Prognostics and Health Management Applications in Nuclear Power Plants
}

\author{
Jamie Coble ${ }^{1}$, Pradeep Ramuhalli ${ }^{2}$, Leonard Bond ${ }^{3}$, J. Wesley Hines $^{4}$, and Belle Upadhyaya ${ }^{5}$ \\ ${ }^{1,4,5}$ University of Tennessee, Knoxville, TN, 37996, USA \\ jcoble1@utk.edu \\ jhines2@utk.edu \\ bupadhya@utk.edu \\ ${ }^{2}$ Pacific Northwest National Laboratory, Richland, WA, 99352, USA \\ pradeep.ramuhalli@pnnl.gov \\ ${ }^{3}$ Iowa State University, Ames, IA, 50011, USA \\ bondlj@iastate.edu
}

\begin{abstract}
The US operating fleet of light water reactors (LWRs) is currently undergoing life extensions from the original 40year license to 60 years of operation. In the US, 74 reactors have been approved for the first round license extension, and 19 additional applications are currently under review. Safe and economic operation of these plants beyond 60 years is now being considered in anticipation of a second round of license extensions to 80 years of operation.

Greater situational awareness of key systems, structures, and components (SSCs) can provide the technical basis for extending the life of SSCs beyond the original design life and supports improvements in both safety and economics by supporting optimized maintenance planning and power uprates. These issues are not specific to the aging LWRs; future reactors (including Generation III+ LWRs, advanced reactors, small modular reactors, and fast reactors) can benefit from the same situational awareness. In fact, many small modular reactor (SMR) and advanced reactor designs have increased operating cycles (typically four years up to forty years), which reduce the opportunities for inspection and maintenance at frequent, scheduled outages. Understanding of the current condition of key equipment and the expected evolution of degradation during the next operating cycle allows for targeted inspection and maintenance activities. This article reviews the state of the art and the state of practice of prognostics and health management (PHM) for nuclear power systems. Key
\end{abstract}

Jamie Coble et al. This is an open-access article distributed under the terms of the Creative Commons Attribution 3.0 United States License, which permits unrestricted use, distribution, and reproduction in any medium, provided the original author and source are credited. research needs and technical gaps are highlighted that must be addressed in order to fully realize the benefits of PHM in nuclear facilities.

\section{INTRODUCTION}

Recent years have seen major shocks to the nuclear power community, including those due to events at Fukushima and subsequent plant closures, such as those in Germany, and changes in economics in the USA due to the widespread availability of cheap natural gas following the introduction of hydraulic fracturing, which is causing some nuclear power plant closures. The global energy situation is further complicated by the growing need for energy to support development and by political uncertainty. In spite of these challenges, global interest in nuclear power persists, with interest in maintaining and extending the safe, economic operation of the approximately 437 reactors currently in service, 73 new reactors being constructed, and as many as 481 reactors planned or proposed for construction (Nuclear Energy Insider, 2014). The operating U.S. fleet includes 100 light water reactors. In addition, there are now (as of December 2014) four new AP-1000 nuclear plants under construction in the United States and one delayed plant being completed by the Tennessee Valley Authority (TVA) at the Watts Bar site. There is also interest in the United States in SMRs, most of which have longer operating periods between planned refueling and maintenance outages than currently operating LWRs. Renewed worldwide interest in nuclear power has been somewhat tempered by the March 2011 incident at Fukushima Dai-ichi in Japan, as well as recent changes in oil and gas production that may change the economics of electricity generation in the US and abroad. However, nuclear power is still considered a 
key element in meeting future worldwide goals for sustainable energy, energy security, and greenhouse emissions.

Currently, three separate thrusts to safe and economic nuclear power development for energy security are being pursued in the United States: (i) longer term operation for the legacy fleet, considering operating lives of 60-80 years; (ii) near-term new nuclear plants with a 60-year design life; and (iii) small modular reactors, which are expected to employ light water reactor technology at least in the medium term (e.g., integral pressurized water reactors iPWRs). Within these activities, attention is turning to enhanced methods for plant component and structural health management.

Safety, reliability, and economics are key drivers for the nuclear power industry. Greater situational awareness of the condition of key SSCs and the operating environment is crucial to meet these needs in legacy and future nuclear power plants (NPPs).

Operational experience (with the light water fleet in the United States and overseas, heavy water fleet, and limited numbers of operating advanced reactors) has shown that greater situational awareness of the state of safety-critical nuclear plant systems, structures, and components is necessary, particularly as they age due to exposure to harsh service conditions. While replacement of a subset of components is possible, and may even be economically attractive, it may be economically prohibitive to replace several of the larger components, including the reactor pressure vessel, primary piping, and some instrumentation cabling (Bond, Doctor, Jarrell, \& Bond, 2008). Thus, characterization, management, and mitigation of agingrelated degradation in these critical passive components becomes important to maintain safety margins. In this context, the technical challenges related to detecting, characterizing, monitoring, and managing materials degradation need to be identified and addressed (Bond, Doctor, Griffin, Hull, \& Malik, 2011; Chockie, Bjorkelo, Fleming, Scott, \& Enderlin, 1991). These challenges are not unique to the operating fleet of LWRs, as the next generation of nuclear power reactors is expected to have similar requirements for managing and mitigating degradation; therefore, it is likely that any technology developed for detecting and characterizing degradation will have applications beyond the current fleet. In fact, experience with the existing NPP fleet suggests that future reactors would benefit from the design-for-inspectability concept, wherein SSC design is altered or additional monitoring capability is designed in at critical locations to enable detection and mitigation of potential failure modes (Nakagawa et al., 2006).

The key technology developments necessary for detecting and managing degradation in reactor components are: (1) nondestructive measurement methods and analysis to detect degradation and anomalies, (2) algorithms to characterize and monitor the state of degradation for the component, and (3) algorithms that use the state of degradation information to determine remaining useful life (RUL) and probability of failure (POF) of the component. Prognostic results can be used to manage the evolving health and condition of nuclear plant SSCs. The POF information may then be used in a probabilistic risk assessment (PRA) model to assess the risk significance of the degradation and the corresponding reduced safety margin. RUL estimates and associated uncertainties can also be used to provide advisory input to plant engineers for operations and maintenance (O\&M) planning or in automated optimal control algorithms. Together, these technologies constitute PHM systems. Ideally, degradation detection should occur early in the degradation development lifecycle, to enable the application of appropriate mitigation or repair actions, thereby maintaining the necessary safety margins. Appropriate PHM systems therefore can potentially preclude serious consequences due to aging-related faults.

A 2012 report by the authors reviewed the current state of monitoring, prognostics, and health management in NPPs (Coble, Ramuhalli, Bond, Hines, \& Upadhyaya, 2012). This article summarizes the results of that survey and incorporates additional advances that have been made in the intervening years. Section 2 describes the PHM needs and opportunities in the current and future NPP fleet. Section 3 summarizes research and applications of online monitoring (OLM) and PHM for nuclear power facilities. Remaining research needs and technical gaps are outlined in Section 4. Finally, section 5 summarizes this review of the state of the art in PHM for the nuclear industry.

\section{The Current and Future Nuclear Power Fleet}

The current US fleet of operating power reactors includes approximately 100 LWRs, the majority of which began commercial operation in the 1970 s and 80 s. These LWRs are currently undergoing life extensions from the original 40 -year license to 60 years of operation; some utilities are looking toward a possible second extension to an 80-year life. In the US, 74 reactors have been approved for the first round license extension, and 19 additional applications are under review (USNRC, 2014). In addition to extending the operating life beyond initial specifications, plants are implementing power uprates; 19 plants have been approved for power uprates since 2011 and eight more applications are under review (USNRC, 2013).

In addition to the existing fleet, several additional LWRs are planned or under construction. TVA is completing construction of a previously uncompleted unit at Watts Bar, Watts Bar Nuclear Plant Unit 2. An additional uncompleted unit at Bellefonte is under consideration for completion by TVA in the near future. Four AP1000s are currently under construction with planned operation beginning between 
2016 and 2018. There is also near-term interest in LWRbased SMRs.

Longer-term interests focus on advanced reactor designs that use non-light water coolants (e.g., molten salt, liquid metal, gas), so-called Generation IV and the associated SMR designs. Advanced reactor designs present additional challenges due to extended operating cycles and lifetimes, harsher operating environments, and new component designs. Advanced- and LWR-based SMRs can support new operating paradigms, such as load-following and dual missions (e.g., electricity production coupled with water desalination, district heating, or hydrogen production).

Advanced component designs, such as smart pumps, are already being deployed to support condition-based maintenance (CBM) based on monitoring and diagnostic results. Additionally, as new plants come online and existing plants are upgraded, new instrumentation and control (I\&C) technologies will support PHM in NPPs. The adoption of digital I\&C systems in legacy plants has been slow, and upgrades have largely been incremental and applied where digital systems can replace existing analog systems one-to-one. Although fully digital I\&C systems have been deployed widely outside the US, the first digital I\&C system in a US NPP was deployed at Oconee Nuclear Station in 2011 (Hashemian, 2011a).

The high cost of radiation-resistant instrumentation cable makes wireless sensor networks attractive, particularly for aging systems that may require additional sensing capabilities to support OLM or replacement of aging instrumentation and cables. Several issues must be resolved before wireless sensor networks are ubiquitously adopted in NPPs for safety-related I\&C applications, including coexistence, reliability, signal propagation, and regulatory impact (Howlader, Ewing, \& Dion, 2010). Wireless sensor networks have been deployed in two facilities for equipment condition monitoring data transmission as part of a U.S. Department of Energy (DOE) Small Business Innovation Research (SBIR) project: Comanche Peak Nuclear Power Plant in Texas and the High Flux Isotope Reactor (HFIR) at Oak Ridge National Laboratory (ORNL) (Hashemian, 2011b; Hashemian, Kiger, Morton, \& Shumaker, 2011). Additionally, the integration of signals from existing wired sensors and new wireless sensors in existing LWRs can provide a holistic view of the health of SSCs and processes, further improving safety and performance in legacy plants.

O\&M costs comprise approximately $60-70 \%$ of the overall generating cost in NPPs, while only $15-30 \%$ of costs are attributed to fuel. Furthermore, of the O\&M costs in U.S. plants, approximately $80 \%$ are labor costs (Wacker et al., 2007). The use of PHM has potential to impact the economics of maintenance for both active components (e.g., pumps, valves, motors) and passive structures (e.g., concrete structures, reactor vessels, buried pipes) (Bond, Doctor, Jarrell, et al., 2008). Equipment maintenance has some associated fixed cost for labor, repair and replacement parts, and the minimum necessary downtime for repair. Unscheduled maintenance due to unexpected equipment degradation or failure can incur significant additional costs, including possible secondary degradation or failure that may result from an in-service equipment failure. The time needed to perform unscheduled maintenance may be extended due to a lack of necessary parts, equipment, and crew and the added repair time for secondary failures. The lost revenue from reduced or halted electricity production during this extended repair time is a significant cost, estimated at approximately $\$ 1.25$ million per day of plant shutdown for an average plant in the United States (NEI, 2011). Obviously, it is of paramount importance to be aware of impending SSC failures so that preventive maintenance can be performed, operations can be adjusted, or auxiliary equipment can be employed to avoid these costs when possible. Information from online monitoring (diagnostics) and prognostics enables turning unscheduled maintenance actions (resulting from unexpected malfunction of SSCs) into scheduled work. No formalized cost-benefit analysis for applying PHM in a specific NPP has been found; however, analyses suggest that fleet-wide savings of over $\$ 1$ billion per year are possible in the United States alone when PHM is applied to all key equipment in legacy power plants (Bond, Ramuhalli, Tawfik, \& Lybeck, 2011).

Considering the lessons learned in operating and maintaining the existing fleet of NPPs, new reactors will clearly benefit from including advanced monitoring, fault detection, diagnostic, and prognostic infrastructure from initial design through operation. Retrofitting health monitoring systems to existing plants is more costly and likely more complicated than incorporating the necessary monitoring systems in the design phase. However, in both legacy and future plants, the economics of PHM for NPPs is attractive (Bond, Ramuhalli, et al., 2011).

\section{Modeling ANd ANALysis fOR PHM}

Full health monitoring systems are the focus of much research. Kothamasu, Huang, and VerDuin (2006) describe prognostics as part of a full CBM system. The authors describe using prognostic estimates to aid maintenance scheduling and planning; they also suggest prognostics for optimal control algorithms. Pipe (2008) and Hess, Calvello, and Frith (2005) suggest the use of RUL estimates for maintenance planning and logistics systems. Callan, Larder, and Sandiford (2006) outline a five-step CBM system which includes: Data Acquisition, Data Manipulation, Condition Monitoring, Health Assessment, and Prognostics. By applying the entire suite of modules, one can accomplish the goals of most prognostic systems: increased productivity; reduced downtime; reduced number and severity of failures, particularly unanticipated failures; optimized operating performance; extended operating periods between 
maintenance; reduced unnecessary planned maintenance; and reduced life-cycle cost.

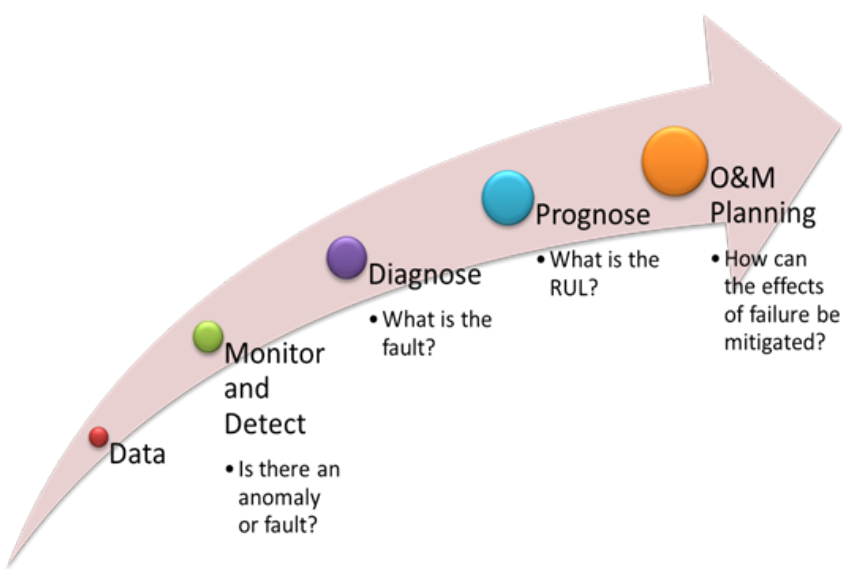

Figure 1. Suite of Modules in a Health Management System (Hines, Garvey, Preston, et al., 2008)

The suite of modules typically included in a full PHM system is shown in Figure 1. Data collected from a system of interest are monitored for deviations from expected behavior. If an anomaly is detected, it is often important to identify the cause of the anomaly; systems will likely degrade in different ways depending on the type of fault and operational stressors and so different prognostic models will be applicable. Finally, a prognostic model is employed to estimate the RUL of the system. The following sections briefly introduce algorithms and approaches for each of the key modules in the PHM system: monitoring and detection, diagnostics, and prognostics. Table 1 summarizes the state of maturity of diagnostic and prognostic analysis for a variety of application spaces; the final three entries summarize the state of maturity in the nuclear power industry, which lags behind other industries and applications.

Table 1. Assessment of State of Maturity for Diagnostic [D] and Prognostic [P] Technologies (adapted from (Bond, Doctor, Jarrell, et al., 2008; Howard, 2005))

\begin{tabular}{|c|c|c|c|c|}
\hline Diagnostic/Prognostic Technology for: & $\mathbf{A} \mathbf{P}^{(\mathbf{a})}$ & $\mathbf{A}^{(\mathbf{b})}$ & $\mathbf{I}^{(\mathbf{c})}$ & $\mathrm{NO}^{(\mathrm{d})}$ \\
\hline $\begin{array}{l}\text { Basic Machinery (motors, pumps, } \\
\text { generators, etc.) }\end{array}$ & $\mathrm{D} \& \mathrm{P}$ & & & \\
\hline $\begin{array}{l}\text { Complex Machinery (helicopter } \\
\text { gearboxes, etc.) }\end{array}$ & $\mathrm{D} \& \mathrm{P}$ & & & \\
\hline Metal Structures & $\mathrm{D}$ & $\mathrm{P}$ & & \\
\hline Composite Structures & & $\mathrm{D}$ & $\mathrm{P}$ & \\
\hline Electronic Power Supplies (low power) & $\mathrm{D}$ & $\mathrm{P}$ & & \\
\hline Avionics and Controls Electronics & $\mathrm{D}$ & $\mathrm{P}$ & & \\
\hline Medium Power Electronics (radar, etc.) & $\mathrm{D}$ & $\mathrm{P}$ & & \\
\hline $\begin{array}{l}\text { High Power Electronics } \quad \text { (electric } \\
\text { propulsion, etc.) }\end{array}$ & $\mathrm{D}$ & $\mathrm{P}$ & & \\
\hline Instrument Calibration Monitoring (NPP) & $\mathrm{D}$ & & & $\mathrm{P}$ \\
\hline Active Components (NPP) & $\mathrm{D}$ & & $\mathrm{P}$ & \\
\hline Passive Components (NPP) & & & $\mathrm{D}$ & $\mathrm{P}$ \\
\hline
\end{tabular}

(a) $\mathrm{AP}=$ Technology currently available and proven effective (b) $\mathrm{A}=$ Technology currently available, but V\&V not completed

(c) $\mathrm{I}=$ Technology in process, but not completely ready for $\mathrm{V} \& \mathrm{~V}$.

(d) $\mathrm{NO}=$ No significant technology development in place.

\subsection{Monitoring and Anomaly Detection}

Monitoring can be accomplished through a variety of methods, including first principle models, empirical models, and statistical analysis (Hashemian, 1995; Heo, 2008; Hines \& Seibert, 2006a; Ramachandran, Fathi, \& Rao, 2010). The monitoring module can be considered an error correction routine; the model gives its best estimate of the true value of the system variables. These estimates are compared to the data collected from the system to generate a time-series of residuals. Residuals characterize system deviations from normal behavior and can be used to determine if the system is operating in an abnormal state. Several reviews of anomaly detection routines are available (Angeli \& Chatzinikolaou, 2004; Gertler, 1988; Isermann, 1984; Miljkovic, 2011). Typically, anomalies can be detected through simple thresholding techniques or hypothesis testing. A common hypothesis test for anomalous behavior is the Sequential Probability Ratio Test (SPRT) (Wald, 1945). This statistical test considers a sequence of residuals and determines if they are more likely from the distribution that represents normal behavior or a faulted distribution, which may have a shifted mean value or altered standard deviation from the nominal distribution. When an anomaly is detected, the source of the anomaly should be diagnosed in order to attribute it to its specific cause.

\subsection{Diagnostics}

Diagnostics may include both fault isolation and fault identification. Fault isolation locates the fault to a specific component or area of a structure. Fault identification determines the root cause of the fault. Often, these analyses are completed in concert with each other; when an anomaly is detected, the diagnostic system typically determines both the location and cause (and, in some cases, severity) of the fault given the available fault symptoms. Fault symptoms include the signatures that may help diagnose the fault, including sensed data, features extracted from sensed data, monitoring system residuals, and anomaly detection results.

Expert systems, such as rule-based and fuzzy rule-based systems, are common fault diagnosers (Milne, 1987; Rich \& Venkatasubramanian, 1987). However, these systems can become unmanageable as the total number of rules increases to accommodate many fault modes and fault symptoms. In addition to expert systems, many traditional and advanced classification algorithms have been applied to fault diagnostics, including k-nearest neighbors ( $\mathrm{kNN}$ ), principal component analysis (PCA), neural networks, self-organizing maps, clustering, fuzzy clustering, etc (Venkatasubramanian, Rengaswamy, \& Kavuri, 2003; Venkatasubramanian, Rengaswamy, Kavuri, \& Yin, 2003; Venkatasubramanian, Rengaswamy, Yin, \& Kavuri, 2003). 
A thorough review of both model-based diagnosis and datadriven diagnosis is given in (Yang, 2004).

The evolving degradation and condition of SSCs will typically be unique for different fault modes. Once the fault has been diagnosed, the RUL can be estimated through appropriate prognostic models.

\subsection{Prognostics}

Prognostic algorithms can be loosely classified into physicsbased and empirical models. Physics-based models rely on an explicit representation of the underlying physics of failure to describe the evolving condition of SSCs (Pecht \& Dasgupta, 1995). Often, the underlying physical processes leading to failure are not completely understood, and simplifying assumptions must be made to facilitate model development. Assumptions made in model development may not be fully applicable to real world systems, which limits the applicability of physics of failure models. As the SSCs, fault modes, and physics of failure become more complicated, these models may be computationally expensive and may not be amenable to rapid analysis and decision-making. Physics-based models may be preferable for high-cost, high-risk SSCs for which the failure data needed to develop empirical models may not exist. Physicsbased models have been widely studied for electronic components (Oja, Line, Krishnan, \& Tryon, 2007; Valentín, Osterman, \& Newman, 2003).

Empirical prognostic models use data to model the relationships seen in real world operation and failure (Hines, Garvey, Preston, et al., 2008; Schwabacher, 2005; Schwabacher \& Goebel, 2007). These models typically provide no insight into the physical mechanisms leading to failure, and instead exploit the correlations between observable or inferable condition indicators and RUL. Empirical models may be preferable to physics of failure models because they are simple to develop, they capture real world relationships, and they require no expertise in the underlying physical phenomena leading to failure. However, empirical models rely on historic data for model development. As such, these models are generally only applicable to systems operating within the range of the data used for model training and development. This poses additional problems for prognostics models, which rely on run-to-failure data for model training. Very few expensive or safety critical systems are allowed to run to failure, particularly in the nuclear power industry; in this case, physics of failure models may be used to simulate failure data for model development. This alleviates the burden of collecting failure data for expensive or safety critical systems, but affords the benefits of empirical methods for prognostics.

Hybrid methods have also been proposed that combine physics-of-failure information with data and empirical modeling methods. Kacprzynski, et al. mitigate the inaccuracies due to simplifying assumptions in physicsbased models of gears (Kacprzynski et al., 2002) and helicopter gearboxes (Kacprzynski et al., 2004) by fusing the results with other data sources including diagnostic results, prognostic architectures, inspection information, and real-time system level features.

\section{PHM APPLICATIONS AND TECHNOLOGIES IN NPPS}

The targets of OLM and PHM for NPPs can be categorized into active and passive SSCs (Table 2). Simply put, active SSCs must move to perform their normal, intended function, while passive SSCs should not. Active components include pumps, motors, generators, sensors, and control rod drives. Passive components include structures, pressure vessels, heat exchangers, cables, pipes, pressurizers, and steam generators. The distinction between active and passive components can be complicated. For instance, pumps and valves are generally considered active components, but their bodies, casings, and support structures are passive. While data analysis algorithms may be commonly applicable, the current approaches for PHM of active and passive components are in some ways distinct.

Table 2: Example Active and Passive SSCs in NPPs

\begin{tabular}{c|c}
\hline Passive SSCs & Active SSCs \\
\hline cables and connections & air compressors \\
\hline containment & batteries \\
\hline containment liner & circuit boards \\
\hline core shroud & control rod drive \\
\hline heat exchangers & cooling fans \\
\hline piping & diesel generators \\
\hline pressurizer & sensors \\
\hline pump casings & motors \\
\hline reactor vessel & pumps \\
\hline steam generators & transistors \\
\hline support structures & valves \\
\hline transformers & power supplies \\
\hline valve bodies & \\
\hline ventilation ducts &
\end{tabular}

The US Nuclear Regulatory Commission (NRC) is charged with ensuring the safe operation of the US fleet of NPPs. During the initial 40-year licensing period, NRC regulations primarily focused on monitoring the performance and maintenance of active components through the Maintenance Rule. The Maintenance Rule provides a performance-based approach to improve the effectiveness of maintenance programs and to integrate risk analysis into maintenance processes (10 CFR 50.65, 2011). A full review of the Maintenance Rule and its application is given by Gregor and Chockie (2006) and Stevenson (2006). While the Maintenance Rule has been adequate for monitoring the effectiveness of maintenance of active components, it does not directly improve the scheduling or economics of performing maintenance. In fact, most maintenance activities of active SSCs in NPPs remain periodically scheduled under the Maintenance Rule; however, well- 
applied CBM could reduce unnecessary maintenance and cost, and its effectiveness could also be monitored under the purview of the Maintenance Rule.

Despite early beliefs that the high standards used to design and fabricate large passive components would preclude degradation during the planned lifetime, unexpected materials degradation has become a concern during the original plant life; an example of such an occurrence is the degradation of the reactor vessel head at the Davis-Besse plant. As utilities started looking to extended operation, the current and evolving condition of large passive SSCs became even more important. Additionally, the failure modes and components of interest have changed over the last five decades (Figure 2). Failures of interest have trended from minor faults in smaller components to potentially catastrophic failures in larger components (e.g., from steam generator tube and bolt failures that appeared early in life to later degradation of shrouds, vessel heads, and pressurizer surge lines).

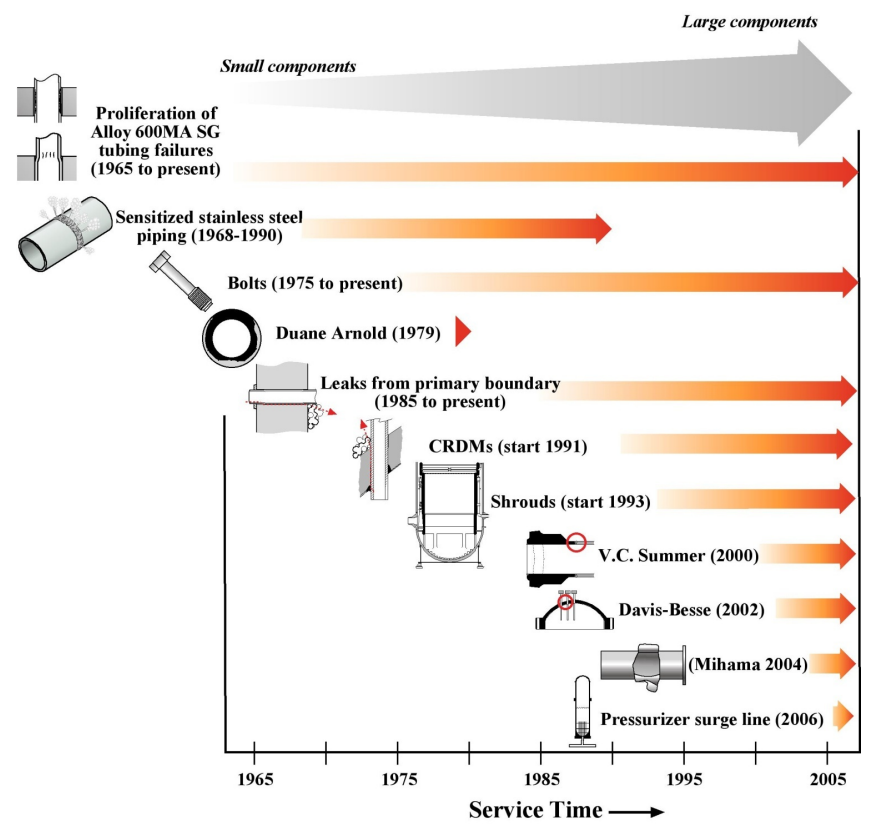

Figure 2. The evolution of passive component failures in NPPs (Staehle, 2010)

To address concerns over materials issues and structural health, the NRC issued Title 10 of the Code of Federal Regulations (10 CFR) Part 54 (10 CFR 54), which mandates aging management plans (AMPs) for large passive structures. The series of Generic Aging Lessons Learned (GALL) reports (USNRC, 2001, 2005a, 2005b, 2010) and the International GALL (IGALL) report (IAEA, 2014) provide the technical basis for evaluating the adequacy of AMPs as plants move in to extended operation. A key component of the AMP is the scheduled in-service inspection (ISI) of passive components codified in $10 \mathrm{CRF}$ 50.55a (10 CFR 50.55a, 2007), including inspection periodicity, inspection techniques, and qualification procedures. More recently, the concept of risk-informed ISI (RI-ISI) is being explored for piping systems (IAEA, 2010); RI-ISI categorizes pipe sections and welds as being of either high or low safety significance based on qualitative and quantitative measures of the risk and consequence of pipe degradation. The AMP is then tailored to ensure that highsafety significance SSCs are inspected, while maintaining some minimum inspection coverage of low-safety significance SSCs. The proposed approach to RI-ISI, however, does not explicitly incorporate the nondestructive evaluation (NDE) measurements or resulting prognosis. The selection of components and the inspection interval are largely based on industry data, operating history, and expert judgment.

Some progress is being made by early adopters of online monitoring and equipment condition assessment in NPPs, such as Électricité de France (EdF) and Exelon, who are deploying 700 units with centralized diagnostic monitoring. In general, however, the nuclear power community is slower to adopt on-line health monitoring than other industries.

Because many utilities own multiple reactor units (some as many as fifteen (IAEA, 2008)), there is interest in developing capabilities to monitor a fleet of plants, either at the utility level or across multiple utilities. Centralized, fleet-wide monitoring provides a myriad of benefits: more examples of key degradation modes, application of common models and analyses, ease of sharing knowledge and results across plants for common equipment and systems, and substantial savings in the implementation of OLM and PHM systems (IAEA, 2008). The Electric Power Research Institute (EPRI), in conjunction with Expert Microsystems, has developed a suite of tools for monitoring high-value assets in electrical generation systems, detecting and identifying faults, and estimating remaining useful life (Agarwal, Lybeck, Bickford, \& Rusaw, 2014). The FleetWide Prognostic and Health Management (FW-PHM) Suite leverages fault signatures and data collected across the US fleet of electricity generating stations, including both nuclear and non-nuclear facilities. The FW-PHM software suite utilizes expert knowledge of fault and remaining life signatures to provide the link between anomaly detection and the creation of actionable information (diagnostics and prognostics). The fault signature and prognostic model databases underlying the FW-PHM suite are intended to be living repositories of experience across the fleet of generating stations that capture cause and effect relationships associated with equipment degradation and prognostics.

The following subsections highlight the state of the art and the state of practice in monitoring, fault detection and diagnostics, and prognostics for key active and passive SSCs, respectively. For many of these components, the state of practice does not include prognostics, which has largely 
remained the purview of research in the nuclear power industry (IAEA, 2013).

\subsection{Monitoring and Prognostics for Active Components}

Active components in NPPs include things that must move in order to perform a function, such as pumps, valves, motors, and some sensors. For these active components, PHM systems can capitalize on the process parameters already collected by the plant I\&C system (e.g., temperature, flow, pressure). Pump health may be characterized using discharge pressure and flow; valve operation could be monitored through the changes in flow as the valve position setpoint is changed; and sensor calibration can be monitored and diagnosed through analysis of the data those sensors are collecting. However, for some active components, these process parameters may not be sufficient to detect and differentiate all fault modes and degradation severities. In these cases, additional measurements may be useful or necessary to develop more robust and accurate prognostic models. For instance, rotating components (pumps, motors, and bearings) can be monitored for various defects and degradation through vibration measurements, and electrical signals can provide additional information about the health of motors and motor-driven components. Many of these additional measurements, such as vibration, motor position, or electrical signatures, may largely be obtained autonomously and unobtrusively during operation. The following subsections briefly describe the current state of PHM for application to sensors, motors, pumps, valves, and control rod drives.

\subsubsection{Sensors}

To ensure safe and effective operation of an NPP, sensing and transmitting reliable values for key parameters are central to nuclear power instrumentation for control. Current practice in the United States requires recalibration of process instrumentation channels every 24 months, in practice occurring during each refueling outage. Recalibration is both a labor-intensive and costly process, resulting in longer outages, increased maintenance cost, and additional radiation exposure to maintenance personnel, and it can actually be counterproductive, by introducing errors in calibration of previously acceptable sensors. OLM techniques have been proposed to assess the calibration of sensors using data collected during plant operation (Bickford, Davis, Rusaw, \& Shankar, 2002; Davis et al., 2002; EPRI, 1998; Hashemian, 1995; Hines \& Davis, 2005; Hines, Garvey, Seibert, \& Usynin, 2008a; Hines, Garvey, Seibert, \& Usynin, 2008b; Hines \& Seibert, 2006a). In 2000 , the NRC accepted the generic concept of OLM for sensor calibration assessment and calibration interval extension (USNRC, 2000); however, no US plant has successfully obtained the license amendment necessary to implement calibration interval extension. The Sizewell B
NPP in the United Kingdom does employ OLM for calibration monitoring and has shown that some common types of sensors and transmitters may function reliably and within calibration for 8 years or longer (Hashemian, Morton, Shumaker, Lillis, \& Orme, 2004; Lillis, 2010). Currently, investigations into PHM for sensors and instrumentation is limited to fault detection (i.e., calibration assessment). If a sensor were determined to be out of calibration, current practice would flag that sensor for recalibration at the next maintenance opportunity. However, approaches to mitigate the effects of limited sensor faults and failures have been suggested (Coble, Ramuhalli, Meyer, et al., 2012); development of these mitigation strategies is the focus of ongoing research.

\subsubsection{Motors}

Induction motors, such as those used for motor-operated valves and pumps, are commonly monitored online through vibration testing, electrical signature analysis, and temperature monitoring (Hudson, 1999). The systems currently in place largely either provide only anomaly detection or complete shutdown in the case of impending catastrophic failure. Deployed motor monitoring systems do not currently extend to prognosis of motor life; however, many of these systems appear to be readily extensible to prognostics.

International Atomic Energy Agency (IAEA) (IAEA, 2013) reviews the current state of the art in vibration data collection and analysis, including both stationary and transient signal analysis. Vibration monitoring can detect and diagnose mechanical issues that may affect vibration: shaft misalignment and imbalance, looseness, bearing defect, etc. Korkua, Jain, Lee, and Kwan (2010) propose a network of wireless vibration sensors to detect rotor vibration due to imbalance and to estimate the severity of the imbalance; the authors suggest an extension of this approach to prognosis, though it was not presented.

Motor electrical signature analyses make use of the variations in electrical properties with changing loads and motor malfunctions. For instance, motor current increases with increasing load. Various anomalies and faults also affect motor current, such as valve stroke in motor-operated valves (MOVs), rotor imbalance, cracked rotor bars, loose rotor, and mechanical misalignment (IAEA, 2008). Motor current signature analysis (MCSA) monitors specific frequencies (e.g., line, synchronous, rotational, slip, and sideband frequencies) for signs of impending anomalies and faults (Kumar \& Madhab, 2006; Thomson \& Fenger, 2001). Electrical signature analysis typically requires knowledge of mechanical loads and internal imbalances. Advanced data analysis algorithms have been proposed to account for unknown speed or torque levels in the motor, providing a more robust and sensitive anomaly detection based on MCSA (Eren, Baskirt, \& Devaney, 2005). Voltage 
mismatch has been investigated for early detection of motor winding degradation under power supply unbalance, manufacturing imperfections, and unknown mechanical loads (Trutt, Sottile, \& Kohler, 2002).

Approaches to monitoring the health of motors can often reveal the health of the motor-drive components as well. However, additional methods are available to specifically monitor the pumps and valves themselves for degradation and impending failure. These techniques can be useful in differentiating between faults in the motor itself and faults in the motor-driven components that affect the motor performance. Methods to monitor pumps and valves directly are described in the following subsections.

\subsubsection{Pumps}

The degradation and failure of reactor coolant pumps (RCPs) can cause significant economic losses for NPPs, which have to shut down for extended periods for maintenance and replacement of degraded RCPs. As such, RCPs have received significant research attention for fault detection and diagnosis. Degradation and failure of RCPs and casing are commonly monitored through the reactor coolant pump vibration monitoring system (RCPVMS) (Koo \& Kim, 2000). Jarrell, Sisk, and Bond (2004) identify the primary stressors which cause degradation of centrifugal pumps and formulate deterministic relationships between these stressors and the resulting degradation. Vibration data analyses showed agreement between the motor position indicator, the vibration response, and the dynamic force loading on the bearing in experimental tests. The experiments highlighted a set of correlations that link measurable degradation stressors to resulting degradation rates and failure. However, RCPVMSs do not currently support automated, online analysis of the vibration data to detect and diagnose abnormal conditions.

Existing RCPVMS commonly apply the Fourier transform to vibration data for detection and diagnostics, but this method is only useful for stationary signals. Often, the statistical properties of signals collected from faulted equipment are changing (i.e., not stationary) due to the nature of the fault progression. To better capture and understand the time-dependence of these signals, a timefrequency representation is necessary. Koo and Kim (2000) use the Wigner distribution of the vibration signals to extract frequency information for fault detection and diagnostics. They use a single neural network trained to classify behavior as either normal or one of six faulted conditions: shaft bow, shaft misalignment, unbalance, oilless bearing rub, structure looseness, and shaft crack. Jung and Seong (2006) use the Wigner-Ville distribution, which accounts for cross-interference between different components of a signal, to detect RCP impeller looseness. This approach makes use of power line signals, three-phase voltage, and current, rather than vibration signals. The three-phase voltage is measured from a secondary tap of the potential transformer, and the current from the current transformer output; this allows a non-intrusive measurement that will not interrupt plant operation. The proposed detection method was validated using data collected during heat-up and cool-down phases of operation. The authors corroborate their fault detection results through comparison to RCP vibration monitoring results and visual inspection.

As an alternative to the current RCPVMSs, Singer, Gross, Walsh, and Humenik (1990) developed a SPRT-based fault detection and diagnostic system that was applied to the RCPs at the Experimental Breeder Reactor II (EBR-II) at Argonne National Laboratory. This monitoring system used a network of SPRT tests and if-then rules to (1) detect anomalies in the plant data in real-time and (2) determine if the anomaly was due to sensor or pump degradation. The developed system provided extremely early operator notification of anomalies, diagnosed the most likely fault mode, and recommended corrective actions based on existing operational and emergency procedures. A similar system using SPRT with an expert system for monitoring RCPs based on sensed speed, vibration, power, and discharge pressure measurements was patented by Gross, Singer, and Humenik (1993).

\subsubsection{Valves}

Check valves are critical to safe NPP operation. The NRC has mandated periodic inspection of these valves, which typically involves partial disassembly. Haynes (1990) gives a review of monitoring and diagnostic methods for check valves, focusing on acoustic emission, ultrasonic inspection, and magnetic flux signature analysis, primarily using portable, walk-around monitors. The state of the art at the time indicated that the combination of acoustic emission with either ultrasonic inspection or magnetic flux signature analysis would enable monitoring of all major check valve operating conditions. Several studies have looked at using acoustic emission signals for valve health monitoring. Nakamura and Terada (1985) used high frequency (100 $\mathrm{kHz}+$ ) resonance type acoustic emission sensors to monitor for leaks in pressurizer valves. After accounting for low levels of background noise, the acoustic signal was used to detect leaks and estimate the valve leak rate. Lee, Lee, Kim, Luk, and Jung (2006) took a similar approach to monitoring check valves for two types of failure: disk wear and foreign object intrusion. These two fault modes were detected and diagnosed based on the frequency spectra profiles of the check valve leakage, the peaks of which are strongly dependent on the type of fault. McShane and Ulerich (1992) developed and patented a check valve monitoring system using ultrasonic transducers coupled to a pipe, instead of directly to the valve. This technique measured the fluid turbulence downstream of the valve to assess the condition of the check valve. Ghosh, Varde, and Satheesh (2013) introduce prognostic models for hinge pin wear and 
backstop failure of check valves based on validated physical models and vibration analysis and accelerometer-based tilt measurements; however, they present no results of applying these models.

The condition of MOVs is commonly monitored through off-line operator testing of valves during outages and remote testing methods that rely on accurate first principle models of the induction machine in the MOV. Chai, Lyon, and Lang (1994) developed a first principle model of the motor in an MOV using measureable stator variables. The model accurately estimated motor behavior and pinion and worm gear frequency for normal operation in laboratory tests. It was proposed that these accurate estimations of MOV forces and motions could be used in a diagnostic system; however, none was presented. Arcella, Bednar, Schreurs, and Forker (1994) patented an online valve diagnostic monitoring system that relies on three sensors: a motor current sensor and strain and position sensors coupled to the valve stem. This system utilized some simple data analysis, such as deviations from baseline data and an expert rule-based system for fault diagnosis. Eklund and Upadhyaya (1991) propose an automated approach to MOV diagnostics based on MCSA, valve stem thrust, and switch activation during valve stroking. The authors suggest trending of these parameters for degradation forecasting and maintenance planning, though no results of this trending are presented. Granjon (2011) proposes a method to monitor MOVs relying exclusively on remote electrical measurements, such as supply voltages and currents, without incorporating any internal MOV measurements. The estimated active power is used as an indicator of the stem nut mechanical condition. The results indicate that active power is closely related to internal mechanical phenomena in the MOV; this indicator may be useful for monitoring additional faults and/or components.

Upadhyaya, Zhao, and Lu (2003) give an example of an advanced surveillance, fault detection, and diagnostic system applied to a turbine control valve during transient operation. This approach involves a data-driven model for predicting nominal variable values and a decision-making module for anomaly detection and diagnosis.

McGhee, Galloway, Catterson, Brown, and Harrison (2014) present a similarity-based prognostic model for "sticky valve" failure. Process data are generated from a high fidelity simulator of a combined-cycle gas turbine plant with simulated valve degradation. The valve degradation is primarily linear in nature, indicated by reduced crosssectional area at the valve. The RUL is estimated based on the pressure at the valve exit. No experimental data are presented to support the linear degradation path, but the prognostic results are promising.

By replacing periodic walk-around monitoring with remote monitoring of electrical and acoustic signatures, MOVs can be continuously monitored for degradation and faults. The availability of these online condition indicators would likely provide the information needed to support prognostics, and many of the models developed for condition assessment would likely be extensible to prognostics.

\subsubsection{Control Rod and Element Drive Mechanisms}

Reactor power and reactivity are manipulated through control and shutdown rods (called control elements in some reactors). Several factors can contribute to malfunction of control rods: degradation of the control rod drive mechanism, failure of the rod control electronics, or restriction of rod movement due to dimensional changes in the core (of particular concern in advanced gas-cooled reactors, AGRs). Failure of the control rods to respond accurately and quickly to drive orders can negatively affect plant load or lead to plant shutdown or trip. As these systems age, the number of issues leading to reactor trip has increased, including failure of analog cards, cables, connectors, and power supplies (USNRC, 2015).

Recent work has focused on developing enhanced position indication and condition monitoring and diagnostics for control rod and element drive mechanisms (CRDMs and CEDMs). Enhancement of the digital rod position indication (DRPI) resulted in single step accuracy (as opposed to the 12-step position accuracy previously seen); in situ health assessment of the coil, cable, connectors, and power supply; rod drop timing during any reactor trip; and digital diagnostics of DRPI data (Hashemian, Morton, \& Shumaker, 2009). DRPI data can be used for performance testing, anomaly detection, and diagnostics for the CRDM and the power cabinet and logic cabinet components (McCulley, Morton, Caylor, \& Hashemian, 2013; Morton, Caylor, McCulley, \& Hashemian, 2012). This diagnostic system provides continuous online monitoring of the CRDM and associated hardware. The results obtained from these analyses may be extensible to prognostic systems, but no such studies have been found.

Deformation of the graphite cores in AGRs can inhibit control rod movement. Currently, infrequent channel inspections are supplemented by expert analysis of monitoring data to detect rod movement restrictions due to dimensional changes in the core and control channels. Wallace et al. (2010) developed an automated algorithm to detect restrictions in control rod motion based solely on rod height measurements. Because specific drive orders are not recorded during operation, the rod drive orders are estimated based on the simultaneous movement of groups of rods. The correlation of the estimated control rod drive orders to the measured height indicates which rods are moving in concert with the orders and which are anomalous. Though the method was developed specifically for detecting restriction of rod motion, the authors suggest the same approach for characterizing control rod performance in predictive maintenance regimes. 


\subsection{Monitoring and Prognostics for Passive Components}

Passive SSCs can be further divided into large structures (e.g., pipes, reactor vessel, and concrete structures), which are monitored via NDE, and so-called semi-passive components (e.g., heat exchangers, transformers, and cables), which may be monitored through performance assessments and process parameters. These semi-passive components can be monitored and prognosed in much the same way that active components are considered. Passive structures require alternate data collection methods that typically interrogate the structure (or a select area of the structure) and record responses. The following subsections summarize the key research in select semi-passive components and passive structures.

\subsubsection{Heat Exchangers}

Heat exchanger $(\mathrm{Hx})$ fouling occurs when unwanted material accumulates on the heat transfer surfaces of the hot or cool side of the Hx. This fouling degrades heat transfer performance by increasing the thermal resistivity, which reduces the heat transfer across the boundary, and by reducing the cross sectional area for flow, which increases the pressure drop across the flow path (Kakaq, 1991). Hx condition can be monitored and characterized with process parameters such as inlet and outlet temperature and flow rate on the primary side and inlet water temperature and flow rate and outlet steam flow rate and pressure on the secondary side. A variety of approaches to using these data have been explored, from first-principle models to purely empirical approaches. Wakui and Yokoyama (2008) use physics-based models to predict the shell inside pressure, water outlet temperature, and $\mathrm{Hx}$ performance. These estimated values are compared with the measured values (and calculated performance) to identify deviations and detect deterioration of the $\mathrm{Hx}$; deviations of $2 \%$ of the heat transfer coefficient were detected. Penha, Hines, and Upadhyaya (2002) develop a hybrid model by combining a physics-based model with neural networks to improve the overall model performance. The hybrid model shows improved prediction of both primary- and secondary-side outlet temperature. Although these model results are not used for anomaly detection or prognostics, the approach may allow for more accurate prediction of nominal performance, leading to more accurate anomaly detection and performance trending. Ardsomang, Hines, and Upadhyaya move toward a more data-based technique by applying auto-associative kernel regression to prediction of measured (temperature difference across the primary and secondary sides, primary side flow rate) and calculated parameters (log mean temperature difference). The $\log$ mean temperature difference residual was used as a degradation indicator for detecting and characterizing $\mathrm{Hx}$ fouling; RUL was predicted with an average error of $\sim 10$ hours. Welz, Nam, Sharp, Hines, and Upadhyaya (2014) further update this approach by including additional parameters in the regression model, including calculated primary and secondary heat transfer coefficients, primary inlet pressure, secondary flow rate, etc. A similar general path model resulted in an average error of $\sim 3$ hours. Finally, a purely data-driven approach was taken in (Coble, Humberstone, \& Hines, 2010) where the effects of Hx fouling were seen in the residuals of steam generator exit temperature. A general path model using these residuals as the prognostic parameter was able to predict RUL within $5 \%$ error five months prior to failure. The results reported in the literature suggest that Hx fouling can be detected, diagnosed, and prognosed using process parameters already collected.

\subsubsection{Transformers}

High-voltage transformers are critical to the reliability of the electric transmission grid. Bartley (2003) identifies twelve failure modes, two of which are of particular interest for monitoring and prognostics because of their relative ubiquity in aging transformers: insulation failure and oil contamination. Several monitoring methods exist to detect anomalies and characterize the condition of oil-filled transformers: dissolved gas analysis (Heathcote, 1998), insulating oil quality testing (USDI, 2000, 2003), moisture content measurements (USDI, 2003), various methods of power factor testing, winding resistance and ratio testing, thermography, recovery voltage testing, winding insulating oil monitoring, tap changer monitoring, internal temperature measurement, and others (Lapworth, Jarman, \& Funnell, 1995; Wang, Vandermaar, \& Srivastava, 2002). Several measurements can be obtained online while the transformer is energized (Gavrilovs, 2011). A survey of the literature describing available and developing transformer monitoring techniques indicates that it may be possible to perform prognostics using data that can be collected with existing transformer monitoring technologies. Initial investigations in using existing data sources for prognostics are reported in (Strong, Coble, O'Reilly, \& Hines, 2011) and (Coble, Strong, O'Reilly, \& Hines, 2011).

\subsubsection{Cables}

NPPs have over $1000 \mathrm{~km}$ of cables, including power, control, and instrumentation cables; replacing these cables is widely considered to be too expensive to support long term operation (LTO). Inspection of the full length of cables is also prohibitive. However, cable aging and degradation has emerged as a key concern as cables are exposed to temperature, irradiation, moisture and humidity, local oxygen concentration, vibration, flooding, and other causes of degradation (IAEA, 1997, 2000). Under these conditions, cable insulation and jacket materials may be vulnerable to changes that can challenge the operational reliability of the cables. In fact, licensee data has shown that the number of cable failures is already increasing with 
plant age, even within the rated 40-year lifetime (Villaran \& Lofaro, 2010).

Several laboratory tests are available for cable assessment; however, these tests tend to be destructive (e.g., elongation at break) and require cable samples that have been exposed to the same environments as in-service cables. A number of in-situ cable monitoring techniques are also available: visual inspection, the compressive modulus test, dielectric loss test, insulation resistance and polarization index, AC voltage withstand test, partial discharge test, DC high potential test, step voltage test, infrared thermography, etc., but these all come with significant disadvantages. Many are only applicable to accessible lengths of cable, such as visual inspection and the compressive (or indenter) modulus test. Some techniques require the cable to be disconnected at one or both ends, including the dielectric loss test, insulation resistance and polarization index, AC voltage withstand, DC high potential, and step voltage tests. Additionally, several of the electrical tests involve high voltage, which can damage the insulation during testing (i.e., AC voltage withstand, partial discharge, and DC high potential tests).

Two methods have been developed and demonstrated that overcome these issues: time domain reflectometry (TDR) (IEC, 2010) and line resonance analysis (LIRA) (Fantoni \& Toman, 2006; Fantoni, 2010; Fantoni, Toman, \& Cano, 2009). TDR is currently widely used in NPPs to assess instrumentation cable condition; however, this technique cannot be applied during plant operation because the cable must be disconnected at one end. It detects local, significant anomalies but is not as effective for minor flaws and some insulation degradation, which may be precursors to larger faults. Additionally, the method requires accurate baselines for comparison to determine the location and magnitude of a fault. LIRA overcomes many of the disadvantages of TDR, and can detect small changes in electrical parameters. However, research in LIRA is ongoing. Currently, the test is not simple to perform nor the results to interpret; execution and analysis will need to be largely automated for wide-scale application in NPPs.

\subsubsection{Passive Structures}

Similar measurement capabilities are not as readily available for passive structures. Damage in passive structures takes many forms (e.g., corrosion, chemical species migration causing changes at grain boundaries and cracking) and typically results in a localized change in material properties (e.g., electrical or thermal conductivity, magnetic permeability, and elastic modulus (Raj, Moorthy, Jayakumar, \& Rao, 2003)). Measurements that are sensitive to these discontinuities are generally used to detect damage in passive components in a nondestructive manner. Nondestructive measurement methods available for passive structures include radiography, ultrasonic imaging, visual inspection, electromagnetic inspection (including eddy currents, potential drop methods, etc.), and thermal imaging (Meyer, Bond, Ramuhalli, \& Doctor, 2010; Meyer, Coble, Ramuhalli, \& Bond, 2011). Almost all of these methods (with the exception of visual inspection) are focused on the detection of hidden damage in components, and rely on the interaction of applied energy with the material damage sites. In most cases, the inspection process requires progressive scanning to inspect the entire component, and may require significant intervention (i.e., not autonomous, online, or unobtrusive). Reliable detection and characterization of early degradation below the limits of traditional NDE poses a significant challenge.

Research in accurate monitoring, flaw detection and diagnosis (location and size), and prognostics for passive components is ongoing (Bond, 1999; Meyer, Bond, \& Ramuhalli, 2012), although few PHM systems for passive components have been deployed in operating NPPs to date. One notable exception is the use of acoustic emission to monitor crack growth (Hutton, Friesel, \& Dawson, 1993a; Hutton \& Kurtz, 1985; Hutton, Kurtz, \& Friesel, 1987). The combination of new (and possibly currently unknown) degradation mechanisms and the increase in the number of components that become susceptible to aging-related degradation as plants transition to long-term operations are likely to challenge the capabilities of available ISI technology and application methodologies (Bond, Doctor, Griffin, Hull, \& Malik, 2009; Dobmann, 2006; Doctor, 1988). Current nondestructive evaluation techniques used for ISI are typically applied to detect relatively large flaws that occur near the end of component life. Concerns regarding the ability of available NDE techniques to detect critical flaws in safety-related components in NPPs caused the NRC and other organizations to conduct a series of studies on the reliability of ultrasonic NDE techniques (Doctor, 2007; Miller, 2008).

In order to manage aging, recent years have seen a move towards NDE for early damage detection in NPP materials (Bond, Doctor, et al., 2011; Fantoni et al., 2009). There is a possibility that such early physical damage can be detected as the change of locally averaged material properties with appropriate sensors. There is also growing interest in sensors and technology for on-line monitoring for the detection of early damage in structural materials (Bond, Doctor, \& Taylor, 2008; Inman, Farrar, Lopes, \& Steffen, 2005). A range of acoustic and electromagnetic measurement methods may be suitable, including nonlinear acoustics (Matlack et al., 2012), eddy current (Lois \& Ruch, 2006; Raj et al., 2003), and magnetic Barkhausen emission (Dobmann, 2006; Raj et al., 2003). However, there are still no accepted measurement technologies for the detection and assessment of some degradation mechanisms unique to NPPs, such as void swelling. Recent reviews of monitoring techniques for passive systems are given in (Meyer et al., 2011) and (IAEA, 2013). 
Exceptions (for passive structure nondestructive condition measurements) include wide-area inspection methods such as acoustic emission (AE) monitoring and guided ultrasonic waves $(\mathrm{GW})$. AE relies on the (usually long-range) detection of stress waves that emanate from damage sites, either intrinsically due to the growth process of the damage or as a result of an external applied load to the component. $\mathrm{AE}$ is well suited for online monitoring of passive structures in nuclear power plants, and has been applied for crack growth detection (Ai, Liu, Chen, He, \& Wang, 2010; Harris \& Dunegan, 1974; Hutton, 1993; Hutton, Dawson, Friesel, Harris, \& Pappas, 1984; Hutton, Friesel, \& Dawson, 1993b; Lybeck et al., 2011), leak detection (IAEA, 2008), and loose part monitoring (IAEA, 2008). GW also relies on the interaction of long-range stress waves with damage in the component (Meyer, Ramuhalli, Braatz, \& Doctor, 2012; Rose, 1999). However, GW is an active technique that uses transducers to generate guided waves in the structure, and records the result of the interaction. The guided waves that are used in $\mathrm{GW}$ inspection are able to propagate over long distances (10s of meters) enabling wide-area inspection (Rose, 2002). A brief review of applications of GW for nuclear power plant components is provided in (Meyer, Ramuhalli, et al., 2012). Issues remain with the reliability of sizing based on GW measurements, demonstration of the probability of detection, and appropriately accounting for changes in performance related to temperature.

The methods described above are focused on detecting the presence of damage in materials that result in a change in the local material properties. Inspection methods that rely on modal frequency analysis for structural monitoring have been proposed in other application spaces (Vipperman, 1999; Zimmerman, Shiraishi, Swartz, \& Lynch, 2008). These methods typically use accelerometers to measure displacements at different points in the components and use the result to analyze changes in primary modes of vibration of the structure. Changes in the modal structure are usually correlated to the level of structural damage.

Prognostics and health management for both active and passive components is a key need for maintaining the high level of safety and improving the economics of nuclear power generation moving forward with both LTO and new builds. The development of PHM systems to date has been largely driven by non-nuclear industries and applications, and adapting these developments to NPPs (either LWRs or advanced reactor designs) faces significant challenges. The following section briefly introduces some of the key technical gaps that currently limit the adoption of PHM in nuclear systems.

\section{RESEARCH NEEDS AND TECHNICAL GAPS}

Research in PHM for active and passive SSCs in NPPs is ongoing and active in the laboratory setting; however, development and deployment of solutions in the commercial field has been limited. For the most part, efforts have focused on enhanced methods for fault detection and diagnostics. Several technical gaps exist that preclude or restrict the application of fully developed PHM systems in NPPs, including sensors that can measure the parameters and stressors necessary to assess the health of SSCs; identification of risk-significant components and locations to support optimal sensor placement, particularly in large passive structures; availablility of data and first-principles models describing the complex degradation mechanisms in nuclear components; uncertainty quantification for sensor measurements, models, and RUL estimations; online assessment of prognostic model performance; and verification and validation of advanced models for PHM. Additionally, well-defined methods for incorporating the results of PHM algorithms into a more holistic view of plant operation, maintenance, and decision making are needed to provide a practical advantage for the use of PHM in terms of safety and economics. While some of these gaps are relevant to other areas and industries, the unique operational framework and licensing requirements of nuclear power pose additional challenges.

\subsection{Sensors and Sensor Placement}

Novel methods for the measurement and inspection of large passive structures are needed to provide the information necessary to assess their current and evolving condition. In particular, sensors are needed that can accurately and reliably provide these measurements over long periods of time in harsh environments. Research is ongoing to evaluate the long-term performance of piezoelectric sensors in radiation environments (Parks \& Tittmann, 2011).

Another challenge to applying PHM to NPPs is sensor placement, particularly for passive components. The proposed NDE methods for monitoring passive components offer limited coverage with a single measurement; multiple measurements at different locations (and perhaps multiple types of measurements) will be necessary to provide coverage of an entire passive structure. Due to cost concerns of deploying many sensors (either through retrofitting legacy reactors or embedded in new plant designs), it may not be feasible to provide $100 \%$ coverage of every important passive structure. Risk analyses may be used to determine the components and locations of most interest in monitoring for degradation in order to reduce the monitoring burden. Research in sensor placement for detecting sub-surface cracks in aircraft structures found that the selection of frequency and placement could only be determined with a good understanding of the failure mechanisms and application problem (Teo, Chiu, Chang, \& Rajic, 2009); research in accurate physics-of-failure models of material degradation will be necessary for optimal sensor placement. 


\subsection{Data and Models}

As discussed in Section 3, prediction algorithms for PHM require either data from a population of failures or welldeveloped physics-of-failure models. Because NPPs are safety-critical systems with a high risk to public perception for any abnormal occurrence, components and systems are not allowed to run to failure in situ. However, the development of high-fidelity physics-of-failure models may not be possible for certain failure modes that are not well enough understood. Development of accurate models for monitoring, diagnostics, and prognostics for both active and passive SSCs will require both physics models and experimental data.

\subsection{Uncertainty Quantification}

A systematic analysis of uncertainty can help reveal both reducible and irreducible uncertainty sources to aid in managing the overall RUL uncertainty. Current research trends focus on Bayesian methods for quantifying the uncertainty in both diagnostic and prognostic predictions (Byington, Watson, Edwards, \& Stoelting, 2004; Liang, Kacprzynski, Goebel, \& Vachtsevanos, 2009; Saha \& Goebel, 2008). In addition to understanding and quantifying uncertainty in RUL estimates, we need to understand how uncertainty in each module of a PHM system propagates to later modules and how to control this uncertainty. For example, uncertainty in the data collected from a system will contribute to uncertainty in the fault detection, the diagnosis, and the eventual prognosis. The uncertainty calculated at each stage needs to account for the uncertainty in the stage(s) before it. Additionally, the uncertainties for specific components will propagate through to subsystems, systems, and the plant as a whole.

\subsection{Online Performance Assessment}

Uncertainty quantification can give some indication of prognostic performance metrics, but additional measures are needed to characterize the performance of a prognostic model online. Online performance measures for monitoring, fault detection, and fault diagnostics are well established and understood (Hines, Garvey, et al., 2008a), but performance metrics for prognostics have largely focused on offline analysis of algorithms (Goebel, Saxena, Saha, Saha, \& Celaya, 2011; Saxena, Celaya, Saha, Saha, \& Goebel, 2010a; Saxena, Celaya, Saha, Saha, \& Goebel, 2010b; Saxena et al., 2008). Methods to evaluate the accuracy, robustness, and confidence level of RUL predictions as they are made will determine if the results provide actionable information for O\&M planning.

\subsection{Integration with $O \& M$ Planning and Control}

In addition to the research needed to fully develop and deploy accurate, reliable, robust PHM systems for NPPs, there is a need for research into how these results can be applied for practical improvements in plant safety, operations, and economics. Methods to integrate PHM results into online PRA are being investigated to provide a more realistic view of the risk of operating a specific plant under specific usage conditions (Coble, Coles, Meyer, \& Ramuhalli, 2013). The results of PHM systems could also be incorporated into O\&M planning by determining if an aging component can be operated under planned or reduced loads until the next convenient maintenance opportunity without affecting the safety margins of the plant. The integration of PHM results into risk assessment and O\&M planning can improve the economics of nuclear generation while maintaining high safety margins.

\subsection{Verification and Validation}

Some research has begun to address verification and validation $(\mathrm{V} \& \mathrm{~V})$ for prognostic algorithms, though none specific to the nuclear industry; a review of $V \& V$ research to date is given by Liu et al. (Liu, Yu, Zhang, \& Li, 2011). One significant challenge in V\&V for NPP PHM systems is the lack of statistically sufficient data for testing the variety of algorithms applied across all SSCs. A rigorous V\&V methodology that utilizes available data and high-fidelity models specific to nuclear applications is needed with endorsement by the NRC.

\section{SUMMARY}

Over the years, operational experience has shown that greater situational awareness of the state of safety-critical nuclear plant systems, structures, and components is necessary, particularly as they age over time due to exposure to harsh service conditions. While replacement of a subset of components is possible, it may be economically prohibitive to replace several of the larger components, such as the reactor pressure vessel or primary piping. Thus, detection, management, and mitigation of aging-related degradation in these critical components become important to maintain safety margins. Appropriate PHM systems can potentially preclude serious consequences due to agingrelated faults while supporting the reduction of unnecessary inspection and maintenance that challenges the economics of nuclear generation.

PHM technologies can be beneficial to NPP operations, potentially providing improvements in safety, reliability, uptime, O\&M optimization, and plant economics, both for the current fleet of LWRs and future reactor designs. Additionally, some Gen III/III+, Gen IV, and SMR reactor designs will potentially have increased monitoring needs due to extended fuel cycles, reduced access to critical components, and remote siting with reduced maintenance staff.

While significant research, development, and deployment has occurred for prognostics and health management in several complex and safety-critical industries, the nuclear 
industry has largely lagged behind. Several gaps, both technological and regulatory, will need to be addressed before these methods are deployed in operating NPPs. Some of these needs are specific to the application to NPPs and nuclear components, including high-fidelity physics-offailure models for failure modes of interest in NPPs; experimental failure and aging data for nuclear SSCs; development of long-lived, radiation resistant sensors; and optimal sensor placement strategies for monitoring passive component condition. Some areas of research are more general to the PHM community as a whole (e.g., uncertainty analysis and propagation, online prognostic performance assessment, and verification and validation of PHM algorithms and models), and ongoing research in other fields can likely be leveraged to address these needs for NPPs. Finally, well-defined methods for incorporating the results of PHM algorithms into a more holistic view of plant operation, maintenance, and decision making are needed to provide a practical advantage for the use of PHM in terms of both safety and economics.

\section{ACKNOWLEDGEMENT}

The information presented in this report was developed from material gathered with support from PNNL's Sustainable Nuclear Power Initiative and DOE-NE FY2011 project funding under the Light Water Reactor Sustainability program.

\section{ACRONYMS AND ABbreviations}

10 CFR Title 10 of the Code of Federal Regulations

AE acoustic emission

AGR advanced gas-cooled reactor

AMP aging management plan

CBM condition-based maintenance

CEDM control element drive mechanism

CRDM control rod drive mechanism

DOE Department of Energy

DRPI digital rod position indication

EBR-II Experimental Breeder Reactor II

EdF Électricité de France

EM electromagnetic

EPRI Electric Power Research Institute

FW-PHM Fleet-Wide Prognostics and Health Management

GALL Generic Aging Lessons Learned

GW guided wave

HFIR High Flux Isotope Reactor

$\mathrm{Hx}$ heat exchanger

I\&C instrumentation and control

IAEA International Atomic Energy Agency

IGALL International Generic Aging Lessons Learned

iPWR integral pressurized water reactor

ISI in-service inspection

LIRA line resonance analysis

LTO long term operation

LWR light water reactor
MCSA motor current signature analysis

MOV motor-operated valve

NDE nondestructive evaluation

NPP nuclear power plant

NRC Nuclear Regulatory Commission

O\&M operations and maintenance

OLM online monitoring

ORNL Oak Ridge National Laboratory

PHM prognostics and health management

POF probability of failure

PRA probabilistic risk assessment

RCP reactor coolant pump

RCPVMS reactor coolant pump vibration monitoring system

RI-ISI risk-informed in-service inspection

RUL remaining useful life

SBIR Small Business Innovation Research

SMR small modular reactor

SPRT sequential probability ratio test

SSC systems, structures, and components

TDR time domain reflectometry

TVA Tennessee Valley Authority

NDT nondestructive test

\section{REFERENCES}

10 CFR 50.55a. (2007). Codes and Standards.

10 CFR 50.65. (2011). Requirements for Monitoring the Effectiveness of Maintenance at Nuclear Power Plants.

10 CFR 54. Requirements for Renewal of Operating Licenses for Nuclear Power Plants. Final Rule (June 1995).

Agarwal, V., Lybeck, N. J., Bickford, R., \& Rusaw, R. (2014). Development of Asset Fault Signatures for Prognostic and Health Management in the Nuclear Industry: Idaho National Laboratory (INL).

Ai, Q., Liu, C.-X., Chen, X.-R., He, P., \& Wang, Y. (2010). Acoustic Emission of Fatigue Crack in Pressure Pipe Under Cyclic Pressure. Nuclear Engineering and Design, 240(10), 3616-3620. doi: 10.1016/j.nucengdes.2010.05.022

Angeli, C., \& Chatzinikolaou, A. (2004). On-Line Fault Detection Techniques for Technical Systems: A Survey. International Journal of Computer Science \& Applications, I(1), 12-30.

Arcella, F. G., Bednar, F. H., Schreurs, J. J., \& Forker, J. M. (1994). 5,329,465.

Ardsomang, T., Hines, J. W., \& Upadhyaya, B. R. Heat Exchanger Fouling and Estimation of Remaining Useful Life.

Bartley, W. H. (2003). Analysis of Transformer Failures.

Bickford, R., Davis, E., Rusaw, R., \& Shankar, R. (2002). Development of an Online Predictive Monitoring System for Power Generating Plants. Paper 
presented at the 45th ISA POWID, San Diego, California.

Bond, L. J. (1999). Predictive Engineering for Aging Infrastructure. Paper presented at the Nondestructive Evaluation of Utilities and Pipelines III, Proceedings of SPIE, Newport Beach, California.

Bond, L. J., Doctor, S. R., Griffin, J. W., Hull, A. B., \& Malik, S. N. (2009). Damage Assessment Technologies for Prognostics and Proactive Management of Materials Degradation (PMMD). Paper presented at the 6th International Topical Meeting on Nuclear Plant Instrumentation, Control, and Human-Machine Interface Technologies, Knoxville, Tennessee.

Bond, L. J., Doctor, S. R., Griffin, J. W., Hull, A. B., \& Malik, S. N. (2011). Damage Assessment Technologies for Prognostics and Proactive Management of Materials Degradation. Nuclear technology, 173(1), 46-55.

Bond, L. J., Doctor, S. R., Jarrell, D. B., \& Bond, J. W. D. (2008). Improved Economics of Nuclear Plant Life Management. Paper presented at the Second International Symposium on Nuclear Power Plant Life Management, Shanghai, China.

Bond, L. J., Doctor, S. R., \& Taylor, T. T. (2008). Proactive Management of Materials Degradation - A Review of Principles and Programs. Richland, Washington: Pacific Northwest National Laboratory.

Bond, L. J., Ramuhalli, P., Tawfik, M. S., \& Lybeck, N. J. (2011). Prognostics and Life Beyond 60 Years for Nuclear Power Plants. Paper presented at the Proceedings of the 2011 IEEE International Conference on Prognostics and Health Management, Denver, Colorado.

Borges, E. M., Filho, F. A. B., \& Guimaraes, L. N. F. (2010). Liquid Metal Flow Control by DC Electromagnetic Pumps. Thermal Engineering, 9(1), 47-54.

Byington, C. S., Watson, M., Edwards, D., \& Stoelting, P. (2004). A Model-Based Approach to Prognostics and Health Management for Flight Control Actuators. Paper presented at the 2004 IEEE Aerospace Conference, Big Sky, Montana.

Callan, R., Larder, B., \& Sandiford, J. (2006). An Integrated Approach to the Development of an Intelligent Prognostic Health Management System. Paper presented at the 2006 IEEE Aerospace Conference, Big Sky, Montana.

Chai, J., Lyon, R. H., \& Lang, J. H. (1994). Non-invasive Diagnostics of Motor-operated Valves. Paper presented at the Proceedings of 1994 American Control Conference (ACC '94), Baltimore, Maryland.

Chockie, A. D., Bjorkelo, K. A., Fleming, T. E., Scott, W. B., \& Enderlin, W. I. (1991). Maintenance
Practices to Manage Aging: A Review of Several Technologies. In USNRC (Ed.). Richland, Washington: Pacific Northwest Laboratory.

Coble, J. B., Coles, G. A., Meyer, R. M., \& Ramuhalli, P. (2013). Incorporating Equipment Condition Assessment in Risk Monitors for Advanced Small Modular Reactors. CHEMICAL ENGINEERING, 33.

Coble, J. B., Humberstone, M., \& Hines, J. W. (2010). Adaptive monitoring, fault detection and diagnostics, and prognostics system for the IRIS nuclear plant. Paper presented at the 2010 Prognostics and Health Management Conference, Portland, OR.

Coble, J. B., Ramuhalli, P., Bond, L. J., Hines, J. W., \& Upadhyaya, B. R. (2012). Prognostics and health management in nuclear power plants: a review of technologies and applications, PNNL-21515: Pacific Northwest National Laboratory.

Coble, J. B., Ramuhalli, P., Meyer, R., Hashemian, H. M., Shumaker, B., \& Cummins, D. (2012). Calibration monitoring for sensor calibration interval extension: Identifying technical gaps. Paper presented at the Future of Instrumentation International Workshop (FIIW), 2012.

Coble, J. B., Strong, E., O'Reilly, S., \& Hines, J. W. (2011). Prognosis of Remaining Useful Life for Large, OilFilled Transformers. Paper presented at the 2011 ANS Winter Meeting and Nuclear Technology Expo - The Status of Global Nuclear Deployment, Washington, D.C.

Davis, E., Bickford, R., Colgan, P., Nesmith, K., Rusaw, R., \& Shankar, R. (2002). On-Line Monitoring at Nuclear Power Plants - Results from the EPRI OnLine Monitoring Implementation Project. Paper presented at the 45th ISA POWID, San Diego, California.

Dobmann, G. (2006). NDE for Material Characterization of Aging Due to Thermal Embrittlement, Fatigue and Neutron Degradation. International Journal of Materials and Product Technology, 26, 122-139.

Doctor, S. R. (1988). Measurement Challenges Associated with Irradiated Reactor Components. Paper presented at the Nondestructive Characterization of Materials in Aging Systems, Materials Research Society Symposium Proceedings, Boston, Massachusetts.

Doctor, S. R. (2007). Nuclear Power Plant NDE Challenges - Past, Present, and Future. Paper presented at the Review of Progress in Quantitative Nondestructive Evaluation, Portland, Oregon.

Eklund, J., \& Upadhyaya, B. (1991). An automated system for motor-operated valve diagnostics. Power Engineering;(United States), 95(12). 
EPRI. (1998). On-Line Monitoring of Instrument Channel Performance. Palo Alto, California: Electric Power Research Institute (EPRI).

Eren, L., Baskirt, O., \& Devaney, M. (2005). Rule-Based Motor Fault Detection. Paper presented at the Instrumentation and Measurement Technology Conference, 2005. IMTC 2005. Proceedings of the IEEE.

Fantoni, P., \& Toman, G. J. (2006). Wire System Aging Assessment and Condition Monitoring Using Line Resonance Analysis (LIRA). Paper presented at the Offshore Wind and Other Marine Renewable Energies in Mediterranean and European Seas (OWEMES), Citavecchia (Rome), Italy.

Fantoni, P. F. (2010). Cable Aging Assessment. Paper presented at the Report from the Light Water Reactor Sustainability Workshop on On-Line Monitoring Technologies, Seattle, Washington.

Fantoni, P. F., Toman, G. J., \& Cano, J. C. (2009). Condition Monitoring of Electrical Cables using Line Resonance Analysis (LIRA). Paper presented at the ANS NPIC\&HMIT 2009 Topical Meeting Nuclear Plant Instrumentation, Controls, and Human Machine Interface Technology, Knoxville, Tennessee.

Gavrilovs, G. (2011). Technical condition asset management of power transformers. Paper presented at the Innovative Smart Grid Technologies (ISGT Europe), 2011 2nd IEEE PES International Conference and Exhibition on.

Gertler, J. J. (1988). Survey of Model-based Failure Detection and Isolation in Complex Plants. IEEE Control Systems, 8(6), 3-11.

Ghosh, A., Varde, P., \& Satheesh, C. (2013). Prognostics \& Health Management of Swing Type Check Valves. International Journal of Emerging Technology and Advanced Engineering, 3(10), 374-382.

Goebel, K., Saxena, A., Saha, S., Saha, B., \& Celaya, J. (2011). Prognostic Performance Metrics. Machine Learning and Knowledge Discovery for Engineering Systems Health Management, 147.

Granjon, P. (2011). Condition Monitoring of MotorOperated Valves in Nuclear Power Plants. Paper presented at the 8th International Conference on Condition Monitoring and Machinery Failure Prevention Technologies (CM/MFPT 2011), Cardiff, Wales.

Gregor, F., \& Chockie, A. (2006). Performance Monitoring of Systems and Active Components. Seattle, Washington: Chockie Group International, Inc.

Gross, K. C., Singer, R. M., \& Humenik, K. E. (1993). $5,223,207$.

Harris, D. O., \& Dunegan, H. L. (1974). Continuous Monitoring of Fatigue-Crack Growth by AcousticEmission Techniques. Experimental Mechanics, 14(2), 71-81.
Hashemian, H. (1995). On-line Testing of Calibration of Process Instrumentation Channels in Nuclear Power Plants. In USNRC (Ed.). Washington, D.C.: U.S. Nuclear Regulatory Commission.

Hashemian, H. M. (2011a). Oconee: the USA's First Fully Digital Nuclear Power Station. Modern Power Systems, 31(1), 73-75.

Hashemian, H. M. (2011b). Wireless Sensors for Predictive Maintenance of Rotating Equipment in Research Reactors. Annals of Nuclear Energy, 38, 665-680.

Hashemian, H. M., Kiger, C. J., Morton, G. W., \& Shumaker, B. D. (2011). Wireless Sensor Applications in Nuclear Power Plants. Nuclear technology, 173(1), 8-16.

Hashemian, H. M., Morton, G. W., \& Shumaker, B. D. (2009). Advanced digital rod position indication system for existing and next generation nuclear reactors.

Hashemian, H. M., Morton, G. W., Shumaker, B. D., Lillis, D., \& Orme, S. (2004). Calibration Reduction System Implementation at the Sizewell B Nuclear Power Plant. Paper presented at the 4th International Topical Meeting on Nuclear Plant Instrumentation, Control and Human Machine Interface Technology, Columbus, Ohio.

Haynes, H. D. (1990). Evaluation of Check Valve Monitoring Methods. Paper presented at the Proceedings of the U.S. Nuclear Regulatory Commission, Seventeenth Water Reactor Safety Information Meeting Rockville, Maryland.

Heathcote, M. J. (1998). J\&P Transformer Book, Twelfth Edition. Oxford, United Kingdom: Elsevier Science Ltd.

Heo, G. Y. (2008). Condition Monitoring Using Empirical Models: Technical Review and Prospects for Nuclear Applications. Nuclear Engineering and Technology, 40(1), 49-68.

Hess, A., Calvello, G., \& Frith, P. (2005). Challenges, Issues, and Lessons Learned Chasing the "Big P": Real Predictive Prognostics. Part 1. Paper presented at the 2005 IEEE Aerospace Conference, Big Sky, Montana.

Hines, J. W., \& Davis, E. (2005). Lessons Learned from the US Nuclear Power Plant On-Line Monitoring Programs. Progress in Nuclear Energy, 46(3-4), 176-189.

Hines, J. W., Garvey, D., Seibert, R., \& Usynin, A. (2008a). Technical Review of On-line Monitoring Techniques for Performance Assessment, Volume 2: Theoretical Issues. Washington, D.C.: U.S. Nuclear Regulatory Commission.

Hines, J. W., Garvey, J., Preston, J., \& Usynin, A. (2008). Tutorial: Empirical Methods for Process and Equipment Prognostics. Paper presented at the 53rd Annual Reliability and Maintainability 
Symposium (RAMS), 2008 Proceedings, Las Vegas, Nevada.

Hines, J. W., Garvey, J., Seibert, R., \& Usynin, A. (2008b). Technical Review of On-line Monitoring Techniques for Performance Assessment, Volume 3: Limiting Case Studies. Washington, D.C.: U.S. Nuclear Regulatory Commission.

Hines, J. W., \& Seibert, R. (2006a). Technical Review of On-Line Monitoring Techniques for Performance Assessment: State-of-the-Art. In USNRC (Ed.), (Vol. 1). Washington, D.C.: U.S. Nuclear Regulatory Commission.

Hines, J. W., \& Seibert, R. (2006b). Technical Review of On-Line Monitoring Techniques for Performance Assessment. Volume 1. State-of-the-Art.

Howard, P. (2005). Prognostic Technology - New Challenges. Paper presented at the Proceedings of the 59th Machinery Failure Prevention Technology (MFPT) Conference, Virginia Beach, Virginia.

Howlader, M. K., Ewing, P. D., \& Dion, J. (2010). Issues Associated with Deploying Wireless Systems in Nuclear Facilities. Paper presented at the 7 th International Topical Meeting on Nuclear Plant Instrumentation, Control, and Human-Machine Interface Technologies (NPIC\&HMIT 2010), Las Vegas, Nevada.

Hudson, B. (1999). HV motor condition monitoring-the end user's view. Paper presented at the Design, Operation and Maintenance of High Voltage (3.3 $\mathrm{kV}$ to $11 \mathrm{kV}$ ) Electric Motors for Process Plant (Ref. No. 1999/178), IEE Colloquium on.

Hutton, P. H. (1993). Listening to Reactor Pressure Boundaries for the Sounds of Cracks and Leaks. Nuclear Engineering International, 38(47), 38-40.

Hutton, P. H., Dawson, J. F., Friesel, M. A., Harris, J. C., \& Pappas, R. A. (1984). Acoustic Emission Monitoring of Hot Functional Testing: Watts Bar Unit 1 Nuclear Reactor. Washington, D.C.: U.S. Nuclear Regulatory Commission.

Hutton, P. H., Friesel, M. A., \& Dawson, J. F. (1993a). Continuous AE crack monitoring of a dissimilar metal weldment at Limerick Unit 1: Nuclear Regulatory Commission, Washington, DC (United States). Div. of Engineering.

Hutton, P. H., Friesel, M. A., \& Dawson, J. F. (1993b). Continuous AE Crack Monitoring of a Dissimilar Metal Weldment at Limerick Unit 1. Washington, DC: U.S. Nuclear Regulatory Commission.

Hutton, P. H., \& Kurtz, R. J. (1985). Acoustic emission for on-line reactor monitoring: Results of intermediate vessel test monitoring and reactor hot functional testing. Nuclear Engineering and Design, 86(1), 311.

Hutton, P. H., Kurtz, R. J., \& Friesel, M. A. (1987). Progress for on-line acoustic emission monitoring of cracks in reactor systems. Nuclear Engineering and Design, 98(2), 135-140.

IAEA. (1997). Pilot Study on the Management of Ageing of Instrumentation and Control Cables - Results of a Coordinated Research Program (1993-1995). Vienna, Austria: International Atomic Energy Agency.

IAEA. (2000). Assessment and Management of Ageing of Major Nuclear Power Plant Components Important to Safety: In-containment Instrumentation and Control Cables. Volume I (pp. 96). Vienna, Austria: International Atomic Energy Agency.

IAEA. (2008). On-line Monitoring for Improving Performance of Nuclear Power Plants - Part 2: Process and Component Condition Monitoring and Diagnostics. Vienna, Austria: International Atomic Energy Agency (IAEA).

IAEA. (2010). Risk-informed In-service Inspection of Piping Systems of Nuclear Power Plants: Process, Status, Issues and Development. Vienna, Austria: International Atomic Energy Agency (IAEA).

IAEA. (2012). Advanced Surveillance Diagnostics, and Prognostics Techniques Used for Health Monitoring of Systems, Structures, and Components in Nuclear Power Plants: CRP Report Volume I. Vienna, Austria: International Atomic Energy Agency (IAEA).

IAEA. (2013). Advanced Surveillance, Diagnostic and Prognostic Techniques in Monitoring Structures, Systems and Components in Nuclear Power Plants IAEA Nuclear Energy Series (Vol. NP-T-3.14). Vienna, Austria: International Atomic Energy Agency.

IAEA. (2014). Approaches to Ageing Management for Nuclear Power Plants: International Generic Ageing Lessons Learned (IGALL) Final Report. Vienna: IAEA TECDOC 1736.

IEC. (2010). Nuclear Power Plants. Instrumentation and Control Important to Safety. Management of Ageing of Electrical Cabling Systems. Geneva, Switzerland: International Electrotechnical Commission (IEC).

Inman, D. I., Farrar, C. R., Lopes, V., \& Steffen, V. (Eds.). (2005). Damage Prognosis. Chichester, West Sussex, England: Wiley.

Isermann, R. (1984). Process Fault Detection Based on Modeling and Estimation Methods-A Survey. Automatica, 20(4), 387-404. doi: 10.1016/00051098(84)90098-0

Jarrell, D. B., Sisk, D. R., \& Bond, L. J. (2004). Prognostics and Conditioned-Based Maintenance: A New Approach to Precursive Metrics. Nuclear technology, 145(3), 275-286.

Jung, J. C., \& Seong, P. H. (2006). An Improved Method for Reactor Coolant Pump Abnormality Monitoring 
Using Power Line Signal Analysis. Nuclear Engineering and Design, 236(1), 57-62.

Kacprzynski, G., Sarlashkar, A., Roemer, M., Hess, A., \& Hardman, B. (2004). Predicting remaining life by fusing the physics of failure modeling with diagnostics. JOm, 56(3), 29-35.

Kacprzynski, G. J., Roemer, M. J., Modgil, G., Palladino, A., \& Maynard, K. (2002). Enhancement of physics-of-failure prognostic models with system level features. Paper presented at the Aerospace Conference Proceedings, 2002. IEEE.

Kakaq, S. (1991). Heat Exchanger Fouling. Boilers, Evaporators, and Condensers, 107.

Koo, I. S., \& Kim, W. W. (2000). The Development of Reactor Coolant Pump Vibration Monitoring and a Diagnostic System in the Nuclear Power Plant. ISA Transactions, 39(3), 309-316.

Korkua, S., Jain, H., Lee, W.-J., \& Kwan, C. (2010). Wireless health monitoring system for vibration detection of induction motors. Paper presented at the Industrial and Commercial Power Systems Technical Conference (I\&CPS), 2010 IEEE.

Kothamasu, R., Huang, S. H., \& VerDuin, W. H. (2006). System Health Monitoring and Prognostics - A Review of Current Paradigms and Practices. The International Journal of Advanced Manufacturing Technology, 28(9-10), 1012-1024.

Kumar, S., \& Madhab, G. (2006). Development of a DSPbased Motor Health Monitoring System. Paper presented at the Industrial Electronics, 2006 IEEE International Symposium on.

Lapworth, J. A., Jarman, P. N., \& Funnell, I. R. (1995). Condition Assessment Techniques for Large Power Transformers. Paper presented at the Proceedings Second International Conference on the Reliability of Transmission and Distribution Equipment (Conf. Publ. No.406), Coventry, United Kingdom.

Lee, J.-H., Lee, M.-R., Kim, J.-T., Luk, V., \& Jung, Y.-H. (2006). A Study of the Characteristics of the Acoustic Emission Signals for Condition Monitoring of Check Valves in Nuclear Power Plants. Nuclear Engineering and Design, 236(13), 1411-1421.

Liang, T., Kacprzynski, G. J., Goebel, K., \& Vachtsevanos, G. (2009). Methodologies for Uncertainty Management in Prognostics. Paper presented at the 2009 IEEE Aerospace Conference, Big Sky, Montana.

Lillis, D. (2010). Use of Online Monitoring to Support Condition Based Maintenance of Safety Category Sensors at Sizewell 'B' Nuclear Power Plant. Paper presented at the 7th International Topical Meeting on Nuclear Plant Instrumentation, Control, and Human-Machine Interface Technologies (NPIC\&HMIT 2010), Las Vegas, Nevada.
Liu, H., Yu, J., Zhang, P., \& Li, X. (2011). Review on Verification and Validation Technology in Integrated Health Management System. Paper presented at the 10th International Conference on Electronic Measurement \& Instruments (ICEMI 2011), Chengdu, China.

Lois, A., \& Ruch, M. (2006). Assessment of Martensite Content in Austenitic Stainless Steel Specimens by Eddy Current Testing. Insight, 48(1), 26-29.

Lybeck, N., Pham, B., Tawfik, M., Coble, J. B., Meyer, R. M., Ramuhalli, P., \& Bond, L. J. (2011). Lifecycle Prognostics Architecture for Selected High-Cost Active Components: INL/EXT-11-22915.

Matlack, K. H., Wall, J. J., Kim, J.-Y., Qu, J., Jacobs, L. J., \& Viehrig, H.-W. (2012). Evaluation of Radiation Damage Using Nonlinear Ultrasound. Journal of Applied Physics, 111(5), 054911-054913.

McCulley, J. R., Morton, G. W., Caylor, S. D., \& Hashemian, H. M. (2013). Advanced Fault Monitoring and Diagnostics for Rod Control and Position Systems in Nuclear Reactors. Paper presented at the Transactions of the American Nuclear Society, Atlanta, GA.

McGhee, M., Galloway, G., Catterson, V., Brown, B., \& Harrison, E. (2014). Prognostic Modeling of Valve Degradation within Power Stations.

McShane, J. L., \& Ulerich, N. H. (1992). 5,115,672.

Meyer, R. M., Bond, L. J., \& Ramuhalli, P. (2012). Online Condition Monitoring to Enable Extended Operation of Nuclear Power Plants. Nuclear Safety and Simulation, 3(1), 31-50.

Meyer, R. M., Bond, L. J., Ramuhalli, P., \& Doctor, S. R. (2010). Advanced Instrumentation, Information, and Control System Technologies: Nondestructive Examination Technologies - NDE Technology for the In-service Inspection of Commercial Nuclear Power Plants: An Assessment Richland, Washington: Pacific Northwest National Laboratory.

Meyer, R. M., Coble, J. B., Ramuhalli, P., \& Bond, L. J. (2011). Advanced Instrumentation, Information, and Control System Technologies: Nondestructive Examination Technologies - FY11 Report. Richland, Washington: Pacific Northwest National Laboratory.

Meyer, R. M., Ramuhalli, P., Braatz, B. G., \& Doctor, S. R. (2012). Application of Acoustic Emission and Other Online Monitoring Technologies to High Temperature Gas Reactors. Richland, Washington: Pacific Northwest National Laboratory.

Miljkovic, D. (2011). Fault Detection Methods: A Literature Survey. Paper presented at the MIPRO, 2011 Proceedings of the 34th International Convention, Opatija, Croatia.

Miller, C. (2008). Nondestructive Evaluation: A Review of NDE Performance Demonstrations - NDE Round 
Robin Report (N. Electric Power Research Institute (EPRI) Nondestructive Evaluation (NDE) Program 1300 W.T. Harris Blvd. Charlotte, Trans.). Palo Alto, California: Electric Power Research Institute.

Milne, R. (1987). Strategies for Diagnosis. IEEE Transactions on Systems, Man and Cybernetics, 17(3), 333-339.

Morton, G. W., Caylor, S. D., McCulley, J. R., \& Hashemian, H. M. (2012). On-Line Condition Monitoring and Diagnostics for Rod Control and Rod Position Indication Systems in Nuclear Reactors. Paper presented at the American Nuclear Society Nuclear Plant Instrumentation and Control and Human-Machine Interface Technology (NPIC\&HMIT), San Diego, CA.

Nakagawa, N., Inanc, F., Frishman, A., Thompson, R. B., Junker, W., Ruddy, F., Dulloo, A., Beatty, J., \& Arlia, N. (2006). On-line nde and structural health monitoring for advanced reactors. Key Engineering Materials, 321, 234-239.

Nakamura, T., \& Terada, M. (1985). Development of Leak Monitoring System for Pressurizer Valves. Progress in Nuclear Energy, 15, 175-179.

NEI. (2011). Nuclear Energy's Economic Benefits - Current and Future (White Paper). Washington, D.C.: Nuclear Energy Institute.

Nuclear Energy Insider. (2014). Nuclear New Construction Market Map 2014.

Oja, M., Line, J., Krishnan, G., \& Tryon, R. (2007). Electronic Prognostics with Analytical Models using Existing Measurands. Paper presented at the 61st Conference of the Society for Machinery Failure Prevention Technology.

Parks, D., \& Tittmann, B. R. (2011). Ultrasonic NDE in a Reactor Core. Paper presented at the 38th Annual Review of Progress in Quantitative NDE, Burlington, Vermont.

Pecht, M., \& Dasgupta, A. (1995). Physics-of-failure: an approach to reliable product development. Paper presented at the Integrated Reliability Workshop, 1995. Final Report., International.

Penha, R. L., Hines, J. W., \& Upadhyaya, B. R. (2002). Monitoring and Diagnosis of a Heat Exchanger Using Hybrid System Modeling. Paper presented at the 3rd Meeting of the Americas - America's Nuclear Energy Symposium, Miami, FL.

Pipe, K. (2008). Practical Prognostics for Condition Based Maintenance. Paper presented at the $1 \mathrm{st}$ International Conference on Prognostics and Health Management (PHM 2008), Denver, Colorado.

Raj, B., Moorthy, V., Jayakumar, T., \& Rao, K. B. S. (2003). Assessment of Microstructures and Mechanical Behaviour of Metallic Materials through Non-destructive Characterisation. International Materials Reviews, 48(5), 273-325.

Ramachandran, K. P., Fathi, K., \& Rao, B. K. N. (2010). Recent Trends in Systems Performance Monitoring \& Failure Diagnosis. Paper presented at the IEEE International Conference on Industrial Engineering and Engineering Management (IEEM 2010), Macao.

Rich, S. H., \& Venkatasubramanian, V. (1987). Modelbased Reasoning in Diagnostic Expert Systems for Chemical Process Plants. Computers \& Chemical Engineering, 11(2), 111-122. doi: 10.1016/00981354(87)80012-1

Rose, J. L. (1999). Ultrasonic Waves in Solid Media. Cambridge, United Kingdom: Cambridge University Press.

Rose, J. L. (2002). A Baseline and Vision of Ultrasonic Guided Wave Inspection Potential. Journal of Pressure Vessel Technology, 124, 273-282.

Saha, B., \& Goebel, K. (2008). Uncertainty Management for Diagnostics and Prognostics of Batteries Using Bayesian Techniques. Paper presented at the 2008 IEEE Aerospace Conference, Big Sky, Montana.

Saxena, A., Celaya, J., Saha, B., Saha, S., \& Goebel, K. (2010a). Evaluating Prognostics Performance for Algorithms Incorporating Uncertainty Estimates. Paper presented at the 2010 IEEE Aerospace Conference, Big Sky, Montana.

Saxena, A., Celaya, J., Saha, B., Saha, S., \& Goebel, K. (2010b). Metrics for Offline Evaluation of Prognostic Performance. Moffett Field, California: Ames Research Center, National Aeronautics and Space Administration.

Saxena, A., Selaya, J., Balaban, E., Goebel, K., Saha, B., Saha, S., \& Schwabacher, M. (2008). Metrics for Evaluating Performance of Prognostic Techniques. Paper presented at the 1st International Conference on Prognostics and Health Management (PHM 2008), Denver, Colorado.

Schwabacher, M. (2005). A Survey of Data-Driven Prognostics. Paper presented at the Proceedings of the AIAA Infotech@Aerospace Conference, Arlington, Virginia.

Schwabacher, M., \& Goebel, K. (2007). A Survey of Artificial Intelligence for Prognostics. Paper presented at the Artificial Intelligence for Prognostics: Papers from the AAAI Fall Symposium, Arlington, Virginia.

Singer, R. M., Gross, K. C., Walsh, M., \& Humenik, K. E. (1990). Reactor Coolant Pump Monitoring and Diagnostic System. Paper presented at the 2nd International Machinery Monitoring and Diagnostic Conference, Los Angeles.

Staehle, R. (2010). Quantitative Micro-Nano (QMN) Approach to Predicting Stress Corrosion Cracking 
in Water Cooled Nuclear Plants [presentation]. Idaho National Laboratory.

Stevenson, J. D. (2006). The Maintenance Rule. In K. R. Rao (Ed.), Companion Guide to the ASME Boiler \& Pressure Vessel Code, Volume 2, Second Edition: Criteria and Commentary on Select Aspects of the Boiler \& Pressure Vessel and Piping Codes (pp. 503-515). New York: ASME Press.

Strong, E., Coble, J. B., O'Reilly, S., \& Hines, J. W. (2011). Feasibility of Prognostics for Transformer Remaining Useful Life Predictions. Paper presented at the MFPT: The Applied Systems Health Management Conference 2011, Enabling Sustainable Systems, Virginia Beach, Virginia.

Teo, Y. H., Chiu, W. K., Chang, F. K., \& Rajic, N. (2009). Optimal Placement of Sensors for Sub-surface Fatigue Crack Monitoring. Theoretical and Applied Fracture Mechanics, 52(1), 40-49. doi: 10.1016/j.tafmec.2009.06.007

Thomson, W. T., \& Fenger, M. (2001). Current signature analysis to detect induction motor faults. Industry Applications Magazine, IEEE, 7(4), 26-34.

Trutt, F. C., Sottile, J., \& Kohler, J. L. (2002). Online condition monitoring of induction motors. Industry Applications, IEEE Transactions on, 38(6), 16271632.

Upadhyaya, B. R., Zhao, K., \& Lu, B. (2003). Fault Monitoring of Nuclear Power Plant Sensors and Field Devices. Progress in Nuclear Energy, 43(14), 337-342.

USDI. (2000). Transformer Maintenance, Facilities Instructions, Standards, and Techniques, Volume 3-31. Washington, D.C.: United States Department of the Interior (USDI), Bureau of Reclamation.

USDI. (2003). Transformer Diagnostics, Facilities Instructions, Standards, and Techniques, Volume 3-31. Washington, D.C.: United States Department of the Interior (USDI), Bureau of Reclamation.

USNRC (2000, July 24, 2000). [Safety Evaluation by the Office of Nuclear Reactor Regulation, Application of On-line Performance Monitoring to Extend Calibration Intervals of Instrument Channel Calibrations Required by the Technical Specifications, EPRI Topical Report (TR) 104965 'On-Line Monitoring of Instrument Channel Performance'].

USNRC. (2001). Generic Aging Lessons Learned (GALL) Report. Washington, D.C.: U.S. Nuclear Regulatory Commission.

USNRC. (2005a). Generic Aging Lessons Learned (GALL) Report - Summary. Washington, D.C.: Office of Nuclear Reactor Regulations, U.S. Nuclear Regulatory Commission.

USNRC. (2005b). Generic Aging Lessons Learned (GALL) Report - Tabulation of Results. Washington, D.C.:
Office of Nuclear Reactor Regulations, U.S. Nuclear Regulatory Commission.

USNRC. (2010). Generic Aging Lessons Learned (GALL) Report - Final Report. Washington, D.C.: Office of Nuclear Reactor Regulations, U.S. Nuclear Regulatory Commission.

USNRC. (2013). Status of Power Uprate Applications. Retrieved 11 August, 2014, from http://www.nrc.gov/reactors/operating/licensing/po wer-uprates/status-power-apps.html

USNRC. (2014). Status of License Renewal Applications and Industry Activities. Retrieved 11 August, 2014, from http://www.nrc.gov/reactors/operating/licensing/re newal/applications.html

USNRC. (2015). LERSearch: Licensee Event Report Database. Retrieved December 4, 2014, from https://lersearch.inl.gov/Entry.aspx

Valentín, R., Osterman, M., \& Newman, B. (2003). Remaining life assessment of aging electronics in avionic applications. Paper presented at the Reliability and Maintainability Symposium, 2003. Annual.

Venkatasubramanian, V., Rengaswamy, R., \& Kavuri, S. N. (2003). A Review of Process Fault Detection and Diagnosis: Part II: Qualitative Models and Search Strategies. Computers \& Chemical Engineering, 27(3), 313-326. doi: 10.1016/s00981354(02)00161-8

Venkatasubramanian, V., Rengaswamy, R., Kavuri, S. N., \& Yin, K. (2003). A Review of Process Fault Detection and Diagnosis: Part III: Process History Based Methods. Computers \& Chemical Engineering, 27(3), 327-346. doi: 10.1016/s00981354(02)00162-x

Venkatasubramanian, V., Rengaswamy, R., Yin, K., \& Kavuri, S. N. (2003). A Review of Process Fault Detection and Diagnosis: Part I: Quantitative Model-Based Methods. Computers \& Chemical Engineering, 27(3), 293-311. doi: 10.1016/s00981354(02)00160-6

Villaran, M., \& Lofaro, R. (2010). Essential Elements of an Electric Cable Condition Monitoring Program. Washington, D.C.: U.S. Nuclear Regulatory Commission.

Vipperman, J. S. (1999). Structural Health Monitoring Applications Using Piezo-dielectric Effects. Paper presented at the The ASME International Mechanical Engineering Congress and Exposition: Adaptive Structures and Material Systems - 1999 (IMECE 1999), Nashville, Tennessee.

Wacker, J. F., Friese, J. I., Casazza, L. O., McKinley, J. P., Petersen, S. L., Wagnon, K. B., Lumetta, G. J., Bonde, S. E., \& Grate, J. W. (2007). FY06 Annual Report on the Progress and Path Forward for the NA-22 Funded Project PL06-AUT308-PD01: 
Automation of Ultra-Trace and Radiochemical Methods. Richland, Washington: Pacific Northwest National Laboratory.

Wakui, T., \& Yokoyama, R. (2008). On-line model-based performance monitoring of a shell-and-tube type heat exchanger using steam and water. Energy Conversion and Management, 49(10), 2669-2677.

Wald, A. (1945). Sequential Tests of Statistical Hypotheses. Annals of Mathematical Statistics, 16(2), 117-186.

Wallace, C., West, G., Jahn, G., McArthur, S., Buckley, G., \& Towle, D. (2010). Control rod monitoring of advanced gas cooled reactors. Paper presented at the Seventh American Nuclear Society International Topical Meeting on Nuclear Plant Instrumentation, Control, and Human-Machine Interface Technologies, NPIC\&HMIT.

Wang, M., Vandermaar, A. J., \& Srivastava, K. D. (2002). Review of Condition Assessment of Power Transformers in Service. IEEE Electrical Insulation Magazine, 18(6), 12-25.

Welz, Z., Nam, A., Sharp, M., Hines, J. W., \& Upadhyaya, B. R. (2014). Prognostics for Light Water Reactor Sustainability: Empirical Methods for Heat Exchanger Prognostic Lifetime Predictions. Paper presented at the Second European Conference of the Prognostics and Health Management Society 2014, Nantes, France.

Yang, Q. (2004). Model-Based and Data Driven Fault Diagnosis Methods with Applications to Process Monitoring. (Ph.D.), Case Western Reserve University, Cleveland, Ohio. Retrieved from http://rave.ohiolink.edu/etdc/view?acc_num $=$ case 1 080246972

Zimmerman, A. T., Shiraishi, M., Swartz, R. A., \& Lynch, J. P. (2008). Automated Modal Parameter Estimation by Parallel Processing within Wireless Monitoring Systems. Journal of Infrastructure Systems, 14(1), 102-113.

\section{BIOGRAPHIES}

Jamie B. Coble received her B.S. degree in Nuclear Engineering and Mathematics from the University of Tennessee in 2005. She completed her MS in Nuclear Engineering in 2006, MS in Reliability and Maintenance Engineering in 2009, and $\mathrm{PhD}$ in Nuclear Engineering in 2010, all at the University of Tennessee. She worked for two years at Pacific Northwest National Laboratory before returning to the University of Tennessee in 2013 as an Assistant Professor of Nuclear Engineering. Her research interests include process monitoring, equipment condition assessment, online risk assessment, and prognosticsinformed control.

Pradeep Ramuhalli received the B.Tech degree from J.N.T. University, Hyderabad (India) in 1995, and the M.S. and Ph.D. degrees in electrical engineering from Iowa State
University, Ames, in 1998 and 2002 respectively. He is currently a senior research scientist at Pacific Northwest National Laboratory (PNNL). Prior to joining PNNL, he was an assistant professor in the Department of Electrical and Computer Engineering at Michigan State University, East Lansing. His research has spanned multiple areas with the goal of measuring system integrity and reliability, and includes sensors, integrated system health monitoring and prognostics, inverse problems, multisensor data fusion, numerical methods, and image/signal processing. Dr. Ramuhalli is a senior member of IEEE, and a member of ANS.

Leonard J. Bond received his B.Sc. in Applied Physics and Ph.D. in Physics, both from the City University London. $\mathrm{He}$ is the Director of the Center for Nondestructive Evaluation (CNDE), and a Professor in both the Aerospace Engineering and Mechanical Engineering Departments, Iowa State University. He has worked as an academic, consultant and as a researcher in national laboratories. His former positions include, Laboratory Fellow at the Pacific Northwest National Laboratory, founding Director CAES, Idaho National Laboratory, Research Professor, University of Colorado at Boulder and University of Denver, and Reader in Ultrasonics, University College London. His research has focused career started with British Gas and has considered modeling and experimentation for ultrasonics, advanced NDE, diagnostics and prognostics. He is co-author of the text Ultrasonics (2011). He has ten patents and more than 300 publications. He is a Fellow, AAAS, the UK Institute of Physics and Senior Member IEEE.

J. Wesley Hines is Postelle Professor and Head of Nuclear Engineering at the University of Tennessee (UT). He received the B.S. degree in Electrical Engineering from Ohio University and was a nuclear qualified submarine officer in the Navy. He has received an MBA, an M.S. in Nuclear Engineering, and a Ph.D. in Nuclear Engineering from The Ohio State University. Dr. Hines teaches and conducts research in process diagnostics, prognostics and condition-based maintenance. His most recent research projects explore the development and use of advanced technologies for component and plant fault detection, identification, and prognostics.

Belle R. Upadhyaya received the Ph.D. degree in Engineering Sciences (Systems Science) from the University of California at San Diego. He is currently a professor of Nuclear Engineering at The University of Tennessee, Knoxville. His research and teaching interests include instrumentation and controls, reactor dynamics, advanced digital signal processing, power and process plant monitoring and diagnosis, autonomous and fault-tolerant control of small modular reactors, nuclear desalination, sensor placement strategies, accelerated aging of detectors and equipment, nondestructive examination, nuclear, and reliability and maintainability engineering. He is a Fellow of 
the American Nuclear Society (ANS), International Society of Automation (ISA), International Society for Engineering Asset Management (ISEAM), and a Life Senior Member of
IEEE. He has published over 350 articles in scientific journals and conference proceedings. 